\title{
Molecular and Functional Diversity of Neural Connexins in the Retina
}

\author{
R. Dermietzel, ${ }^{1}$ M. Kremer, ${ }^{1}$ G. Paputsoglu, ${ }^{1}$ A. Stang, ${ }^{1}$ I. M. Skerrett, ${ }^{3}$ D. Gomès, ${ }^{4}$ M. Srinivas, ${ }^{5}$ \\ U. Janssen-Bienhold, ${ }^{2}$ R. Weiler, ${ }^{2}$ B. J Nicholson, ${ }^{3}$ R. Bruzzone, ${ }^{4}$ and D. C. Spray ${ }^{5}$ \\ ${ }_{1}^{1}$ Department of Neuroanatomy and Molecular Brain Research, Ruhr Universität Bochum, DE-45801 Bochum, Germany, \\ 2Universität Oldenburg, Department of Biology, Carl von Ossietzky Universität, DE-2611 Oldenburg Germany, ${ }^{3}$ Department \\ of Biological Sciences, State University of New York Buffalo, Buffalo, New York 14260, 4/nstitut Pasteur, Unité de \\ Neurovirologie et Régénération du Système Nerveux, F-75724 Paris Cedex 15, France, and ${ }^{5}$ Department of Neuroscience, \\ Albert Einstein College of Medicine, Bronx, New York 10461
}

\begin{abstract}
Electrical synapses (gap junctions) in neuronal circuits have become a major focus in the study of network properties such as synchronization and oscillation (Galarreta and Hestrin, 1999; Gibson et al., 1999). Despite the recent progress made in unraveling the contribution of gap junctions to network behavior, little is known about the molecular composition of the junctional constituents. By cloning gap junction proteins [connexins (Cxs)] from zebrafish retina and through functional expression, we demonstrate that the retina possesses a high degree of connexin diversity, which may account for differential functional properties of electrical synapses. Three new Cxs, designated as zebrafish Cx27.5 (zfCx27.5), zfCx44.1, and zfCx55.5, and the carp ortholog of mammalian Cx43 were cloned. By in situ hybridization and in situ RT-PCR, we demonstrate that the four fish connexin mRNAs show differential localization in the retina. Transient func-
\end{abstract}

tional expression in paired Xenopus oocytes and in the neuroblastoma N2A cell line indicate an extreme range of electrophysiological properties of these connexins in terms of voltage dependence and unitary conductance. For instance, the new zfCx44.1 exhibited high sensitivity to voltage-induced closure with currents decaying rapidly for transjunctional potentials $>10$ $\mathrm{mV}$, whereas zfCx55.5 channels showed an opposite voltage dependence in response to voltage steps of either polarity. Moreover, although zfCx44.1 channels showed unitary conductance as high as any previously reported for junctional channels (nearly $300 \mathrm{pS}$ ), zfCx55.5 and zfCx27.5 exhibited much lower unitary conductances $(<60 \mathrm{pS})$.

Key words: electrical synapses; gap junctions; retina; cloning; zebrafish connexins; functional diversity
Gap junctions provide intercellular conduits for electrical (ionic) and metabolic coupling between almost all cells in multicellular organisms. Gap junctions are composed of connexins (Cxs), a multigene protein family that can be divided broadly into three major branches: the $\alpha, \beta$, and $\gamma$ groups (Kumar and Gilula, 1996; O'Brien et al., 1998). As compared with the wealth of knowledge concerning the molecular composition of non-neuronal gap junctions (for review, see Bennett et al., 1991; Dermietzel and Spray, 1993; Bruzzone et al., 1996), little is known about the molecular identity of the connexins involved in the establishment of electrical synapses at neuronal gap junctions.

The first successful attempt to identify a neuronal connexin has recently been made by O'Brien et al. (1996), who used a skate retinal expression library to clone fish $\mathrm{Cx} 35$, a protein of $35 \mathrm{kDa}$ of molecular mass mainly expressed in the inner nuclear and inner plexiform layers of fish retina (O'Brien et al., 1998). Transcripts of fish $\mathrm{Cx} 35$, the related fish $\mathrm{Cx} 34.7$, and the murine ortholog $\mathrm{Cx} 36$ (Condorelli et al., 1998; Söhl et al., 1998) have been detected in neurons of retina and brain.

The retina consists of a highly ordered laminar structure that comprises three compact layers of neurons separated by two synaptic layers and offers an approachable and attractive model for studying neuronal gap junctions. Gap junction-mediated dye trans-

Received May 8, 2000; revised Aug. 10, 2000; accepted Aug. 17, 2000.

This work was supported in part by Deutsche Forschungsgemeinschaft Grants De. 292/6-1, SFB 509 to R.D. and We 849/12-1 to R.W., RETINA France to R.B., American Heart Association Heritage Postdoctoral Fellowship to M.S. and I.M.S., and National Institutes of Health Grants GM48773 to B.J.N. and NS07512 and NS34931 to D.C.S. We gratefully acknowledge the help of M. Meyer (Heidelberg, Germany) with the in situ RT-PCR.

Correspondence should be addressed to R. Dermietzel, Department of Neuroanatomy and Molecular Brain Research, Ruhr Universität Bochum, Universitätsstrasse 150, DE-45801 Bochum, Germany. E-mail: rolf.dermietzel@ruhr-uni-bochum.de.

Copyright (C) 2000 Society for Neuroscience $0270-6474 / 00 / 208331-13 \$ 15.00 / 0$ fer is found in all cell types that form the neuronal retinal network (Vaney, 1994, 1996; Weiler, 1996; Becker et al., 1998). The systematic use of the cationic tracer Neurobiotin in the retina has led to the discovery of an unexpected high incidence of coupled cells and a diversity of coupling patterns so far unmatched by any other part of the brain (Vaney, 1991). The selective nature of neuronal coupling and its differential regulation by neuromodulators, as shown recently for the amacrine AII cells (Hampson et al., 1994; Mills and Massey, 1995; Weiler et al., 1999), strongly suggests the occurrence of multiple types of connexins within the neuronal populations of this tissue. The analysis of retinal gap junctions has concentrated on horizontal cells, a population of retinal neurons that is endowed with extensive gap junction coupling. Dual cell recording experiments and dye-transfer studies in parallel with freeze-fracture investigation have made horizontal cells by far the best studied class of coupled neurons in the CNS (Dowling et al., 1966; Piccolino et al., 1982; Lasater, 1987; DeVries and Schwartz, 1989; Vaney 1993; Weiler, 1996; Wolburg and Kurz-Isler, 1996; Baldrige et al., 1998).

We have isolated primary neurons from fish retina, a vertebrate species that allows for $>70 \%$ enrichment of horizontal cells, and used RT-PCR with degenerate primers on solitary horizontal cell mRNA to amplify connexin cDNA fragments. Using rapid amplification of cDNA ends (RACE) strategies and screening of both cDNA and genomic DNA libraries from zebrafish, we succeeded in cloning four different connexin cDNAs, three of which are novel sequences. The three new members of the connexin family are designed as zebrafish $\mathrm{Cx} 27.5$ (zfCx27.5), zfCx55.5, and zfCx44.1, on the basis of the theoretical molecular mass of their deduced amino acid (aa) sequences, whereas the fourth is the carp ortholog of mammalian Cx43. In situ hybridization and in situ RT-PCR indicate that these connexins are differentially expressed in the retina. Together with functional expression studies in transiently 
transfected paired Xenopus oocytes and N2A cell lines illustrating significant differences in the biophysical behavior of these connexins, our data provide conclusive evidence that retinal neurons are endowed with a repertoire of distinct connexins that may account for a functional diversification of gap junction-mediated intercellular communication in neuronal networks.

\section{MATERIALS AND METHODS}

Cloning of partial connexin cDNAs from carp retina. Dark-adapted carps, $\sim 20 \mathrm{~cm}$ in length, were kept in an aerated tank before decapitation. Fish retinas were isolated from enucleated eyes, dissected, and incubated for 15 min in oxygenized Leibowitz (L-15) medium, pH 7.4, containing $15 \mu \mathrm{g} / \mathrm{ml}$ papain (Sigma, Deisenhofen, Germany). After enzymatic dissociation, retinas were washed three times in L-15 medium supplemented with $5 \%$ fetal calf serum to stop enzyme activity. Next, mechanical trituration was performed with fire-polished Pasteur pipettes. Cell suspensions corresponding to 10 retinas in $\mathrm{L}-15$ medium were subjected to centrifugation on a $0.8-4 \%$ Ficoll gradient as described previously (Janssen-Bienhold et al. 1993). After sedimentation, cell fractions enriched with horizontal cells were collected and inspected by phase microscopy. Only fractions containing $\sim 70 \%$ horizontal cells recognized by their morphology under phasecontrast light microscopy were used for total RNA extraction according to standard procedure (Chomczynsky and Sacchi, 1987).

Aliquots of $1 \mu \mathrm{g}$ total RNA derived either from enriched horizontal cells or from total retina RNA preparations were reverse-transcribed using random hexanucleotides and standard conditions for Moloney murine leukemia virus reverse transcriptase (Promega, Madison, W I). Degenerate primers complementary to highly conserved regions of selected rat connexins were used in PCR reactions to amplify reverse-transcribed cDNAs (Haefliger et al., 1992); the sense primer (GGC-TGT-RAA-SAA-YGTYGT-CTA-YGA-C), a nested sense primer (TTC-CCC-ATC-TCB-CAYRTB-CG), and the antisense primer (TGG-GVC-KGG-AVA-BGA-AGC AGT) were designed to amplify cDNA fragments spanning the second and third transmembrane domains of connexin proteins, which include the cytoplasmic loop region of variable length. PCR was performed using cDNA equivalents of $1 \mu \mathrm{g}$ of total RNA, standard reaction conditions for Taq-DNA polymerase (Promega), and 30 cycles of the following amplification profile: denaturation for $60 \mathrm{sec}$ at $94^{\circ} \mathrm{C}$, annealing for $60 \mathrm{sec}$ at $55^{\circ} \mathrm{C}$, extension for $90 \mathrm{sec}$ at $72^{\circ} \mathrm{C}$. Amplification products (amplicons) were separated on $1 \%$ agarose gels, extracted, and subcloned in the pGEM3Z vector (Promega) used to transform Escherichia coli JM109. Forty randomly selected transformants were isolated and differentiated by Southern blot hybridization with digoxigenin-11 dUTP-labeled probes, coding for diverse rodent connexins. Probe synthesis was performed as recommended by the manufacturer (Boehringer Mannheim, Mannheim, Germany). Fragments of the transformants that hybridized with probes coding for mouse Cx43, Cx26, and Cx50 were subjected to nucleotide sequencing (ABI 372, PerkinElmer Life Sciences, Foster City, CA). In the following sections, these fragments are indicated as frag 43 , frag 26 , and frag50, respectively. Genomic library screening and $R A C E$ extension. Approximately $5 \times 10^{5}$ plaque-forming units of a zebrafish genomic library in the $\lambda$ phage FixII (Stratagene, Heidelberg, Germany) were plated and screened by standard techniques (Sambrook et al., 1989). Radiolabeled probes were generated from the fragments that hybridized with frag26 and frag50 by random labeling with ${ }^{32}$ P-dATP (Multiprime Labeling Kit, Amersham Pharmacia, Freiburg, Germany). Frag43 was not used for genomic library screening but was used instead for RACE extension to clone carpCx43. Filter hybridization was performed using standard methods (Sambrook et al., 1989) under high stringency conditions $\left(65^{\circ} \mathrm{C}, 2 \times \mathrm{SSC} ; 1 \times \mathrm{SSC}=150 \mathrm{mM} \mathrm{NaCl}\right.$, $15 \mathrm{~mm}$ citrate, $\mathrm{pH}$ 7). After two rounds of rescreening genomic DNAs, recombinant phage clones were isolated using standard methods (Sambrook et al., 1989).

In addition to the screening of the genomic zebrafish library, we performed RACE extension using carp mRNA as a template for the Marathon cDNA Amplification Kit (Clontech Laboratories, Heidelberg, Germany). Sets of gene-specific frag 43 primers were designed according to the sequencing data, obtained by degenerate RT-PCR. RACE extension was performed as indicated by the manufacturer's protocol. RACE extension products were subcloned into pCRII vector (Invitrogen, Groningen, The Netherlands).

The identity of the carpCx43 cDNA obtained by RACE extension was further confirmed by screening a zebrafish cDNA library (gift of Dr. John Dowling, Harvard University) using a RACE fragment of carpCx43.

Multiple tissue Northern blots and RT-PCR. Total RNA was extracted with the TRIzol reagent (Life Technologies, Karlsruhe, Germany) from brain, heart, liver, spleen, retina, kidney, and lens to analyze the expression patterns of retinal connexins in multiple tissues. To get sufficient amounts of RNA, carp tissues were used throughout the hybridization experiments. Total RNA $(20 \mu \mathrm{g})$ was electrophoresed and transferred onto nylon membrane by capillary transfer using $2 \times$ SSC. Hybridization probes were selected on the basis of minimal homologies to known connexin mRNAs. All probes were radiolabeled with ${ }^{32} \mathrm{P}$-dATP by random priming and used in hybridization reactions at $43^{\circ} \mathrm{C}$ with standard procedures (Sambrook et al., 1989).

For cDNA synthesis, aliquots of $1 \mu \mathrm{g}$ of total RNA from carp retina and other tissues were incubated for $15 \mathrm{~min}$ at room temperature with $1 \mathrm{U}$ of DNase (Life Technologies) in the appropriate buffer in a total volume of $10 \mu$. The reaction was stopped by adding EDTA and inactivating the DNase at $65^{\circ} \mathrm{C}$ for $15 \mathrm{~min}$. After incubating the RNA with 50 pmol random hexanucleotides for $10 \mathrm{~min}$ at $70^{\circ} \mathrm{C}$, first-strand synthesis was performed by adding the appropriate reaction buffer, $0.1 \mu$ mol DTT, $10 \mathrm{nmol}$ of each dNTP, and $200 \mathrm{U}$ of reverse transcriptase (Life Technologies) in a total volume of $20 \mu \mathrm{l}$ at $42^{\circ} \mathrm{C}$ for $50 \mathrm{~min}$. The reaction was stopped by inactivating the enzyme at $70^{\circ} \mathrm{C}$ for $15 \mathrm{~min}$. Negative controls were made for each tissue by omitting reverse transcriptase.

PCR was performed under standard conditions using $1 \mu \mathrm{l}$ of the cDNA reaction in 35 cycles. The following primers were used: $\mathrm{zfCx} 44.1$ forward [all nucleotide (nt) positions are referred to by base number according to the full-length sequence; nt 540-663] and reverse primer (nt 1080-958); zfCx55.5 forward primer (nt 365-386) and reverse primer (nt 1032-1040), zfCx27.5 forward primer (nt 393-414) and reverse primer (nt 711-691). The primers for the $\beta$-actin control reaction were forward (nt 226-246) and reverse primer (nt 448-429). Reaction products were separated on $1 \%$ agarose gels and visualized by ethidium bromide staining to confirm the expected size of amplified products.

In situ hybridization and in situ RT-PCR. For the localization of the new zebrafish connexins and carpCx43, we performed in situ hybridization and in situ RT-PCR. Freshly prepared carp and zebrafish eyes were embedded in Tissue-Tek (Miles, Elkhart, IN), frozen, and stored in liquid nitrogen. Cryostat sections of $10 \mu \mathrm{m}$ thickness were collected on sialinized coverslips and stored immediately at $-20^{\circ} \mathrm{C}$.

For in situ hybridization sections, were heat-fixed at $65^{\circ} \mathrm{C}$ for $2 \mathrm{~min}$ and subsequently air-dried for another $20 \mathrm{~min}$. A lipid extraction step was performed for $5 \mathrm{~min}$ in chloroform followed by air drying of the sections for another $5 \mathrm{~min}$. Then sections were fixed for $7 \mathrm{~min}$ in $4 \%$ formalin in PBS, pH 7.0, washed twice in PBS and twice in $2 \times$ SSC. Prehybridization was performed in $15 \mu$ l hybridization buffer $(50 \%$ deionized formamide $10 \%$ dextran sulfate, $1 \times$ Denhardt's buffer) for $1 \mathrm{hr}$. Digoxigenin-labeled cRNA probes for in situ hybridization experiments were synthesized by means of an in vitro transcription kit according to the manufacturer's recommendations (Boehringer Mannheim). Four different antisense probes and the corresponding sense probes were generated from plasmids containing the different subcloned fragments of the new sequences; all positions given below are relative to the start codon ATG: carpCx43 (nt 458-1142), zfCx55.5 (nt 1082-1429), zfCx27.5 (nt 282-711), and zfCx.44.1 (nt 1037-1467). The synthesized probes were selected for minimal homologies with published connexin sequences (GenBank National Center for Biotechnical Information, Washington, DC). All cRNA probes were hybridized to sections in $15 \mu \mathrm{l}$ hybridization buffer for $16 \mathrm{hr}$. Probe concentrations and temperatures of prehybridization and hybridization were adjusted to probe length. CarpCx 43 and $\mathrm{zfCx} 44.1$ were hybridized at $55^{\circ} \mathrm{C}$, at a concentration of $400 \mathrm{ng} / \mathrm{ml}$; $\mathrm{zfCx} 55.5$ and $\mathrm{zfCx} 44.1$ were hybridized at $52^{\circ} \mathrm{C}$ and $200 \mathrm{ng} / \mathrm{ml}$. After hybridization, slides were rinsed once in $2 \times$ SSC and three times in $2 \times$ SSC containing $60 \%$ formamide, for 5 min each, at the corresponding hybridization temperature; twice in $2 \times$ SSC for $5 \mathrm{~min}$ at $37^{\circ} \mathrm{C}$; and twice in $0.1 \times \mathrm{SSC}$ for $5 \mathrm{~min}$, at $37^{\circ} \mathrm{C}$ and room temperature, respectively. Excess of nonhybridized probes was digested with $10 \mu \mathrm{g} / \mathrm{ml}$ RNase A in $2 \times$ SSC for $15 \mathrm{~min}$ at room temperature. For immunological detection of hybridized probes, slices were rinsed twice in Tris-buffered saline (TBS), pH 7.2, blocked with 3\% nonfat milk powder in TBS for 90 min at room temperature, and incubated with an anti-digoxigenin antibody coupled to alkaline phosphatase (Boehringer Mannheim) diluted 1:200 in TBS containing $1 \%$ nonfat milk powder for $2 \mathrm{hr}$. Then, samples were rinsed twice in TBS, incubated for $10 \mathrm{~min}$ in alkaline phosphatase buffer (100 mM Tris/HCl, pH 9.5, $100 \mathrm{~mm} \mathrm{NaCl,} 10 \mathrm{mM} \mathrm{MgCl}_{2}$ ), and stained in the latter buffer containing $340 \mu \mathrm{g} / \mathrm{ml}$ nitro blue tetrazolium and $180 \mu \mathrm{g} / \mathrm{ml}$ 5-bromo-4-chloro-3-indolyl phosphate at $4^{\circ} \mathrm{C}$ overnight. Slices were rinsed once in $10 \mathrm{~mm}$ Tris, pH 8, $1 \mathrm{~mm}$ EDTA, and twice in double-distilled water. After counterstaining with methyl green for $15 \mathrm{~min}$, slices were mounted in aqueous mounting medium (Shandon, Frankfurt, Germany).

For in situ RT-PCR, sections were fixed for $10 \mathrm{~min}$ in $4 \%$ paraformaldehyde in PBS, washed twice in PBS, and incubated in prewarmed buffer before protease digestion. Slides were transferred to a prewarmed incubation tray, and each section was covered with $100 \mu$ l proteinase K solution (2.5 mg/ml proteinase $\mathrm{K}$ in $20 \mathrm{~mm}$ Tris-HCl, pH 7.4, 0.5\% SDS). After 60 min at $37^{\circ} \mathrm{C}$, digestions were stopped by heat inactivation for $1 \mathrm{~min}$ at $95^{\circ} \mathrm{C}$. Slides were then incubated in $100 \%$ ethanol and air-dried. Next, sections were digested at $37^{\circ} \mathrm{C}$ with $50 \mathrm{U}$ of RNase-free DNase I (Sigma) per sample for at least $10 \mathrm{hr}$, washed with bidistilled water, and incubated in $100 \%$ ethanol. For reverse transcription, air-dried sections were incubated with $50 \mu \mathrm{l}$ of reverse transcription reaction mixture including gene-specific primers for first-strand synthesis (Superscript II, Stratagene). Genespecific primers were the same as used for RT-PCR. After $60 \mathrm{~min}$ at $42^{\circ} \mathrm{C}$, reactions were stopped by two washes with ultrapure water, incubated with $100 \%$ ethanol, and air-dried. For PCR, $50 \mu$ reaction mixtures containing $1 \times$ PCR buffer II (PerkinElmer), $2.5 \mathrm{~mm} \mathrm{MgCl} 2,200 \mu \mathrm{M}$ each dNTP, 10 $\mu \mathrm{M}$ digoxigenin-11-dUTP (Boehringer Mannheim), and $0.8 \mu \mathrm{M}$ upstream and downstream primers were added to each section on the preheated $\left(70^{\circ} \mathrm{C}\right)$ GeneAmp In Situ PCR 1000 assembly tool (PerkinElmer). After 10 min, $5 \mathrm{U}$ of AmpliTaq-DNA polymerase (PerkinElmer) was added, and slides were assembled and placed into the thermocycler, preheated to $70^{\circ} \mathrm{C}$ The following protocol was performed: one cycle of $3 \mathrm{~min}$ at $94^{\circ} \mathrm{C}, 35$ 
cycles of $1 \mathrm{~min}$ at $94^{\circ} \mathrm{C}, 1 \mathrm{~min}$ at $56^{\circ} \mathrm{C}$, and $2 \mathrm{~min}$ at $72^{\circ} \mathrm{C}$. After cycling, digoxigenin detection and color development were performed as described for the in situ hybridization analysis. All experiments were performed running the following controls along with experimental samples: +/DNase I-treated controls; $+/-$ the reverse transcription step.

In vitro transcription and translation of zebrafish connexins. For all zebrafish connexins, a DNA fragment containing the entire coding sequence was excised from pBluescript-SKII clones by digestion with appropriate restriction enzymes (zfCx27.5: BglII-ScaI, $1.1 \mathrm{~kb}$; zfCx44.1: HindIIIPstI, $1.5 \mathrm{~kb}$; zfCx55.5 DraI-XbaI, $1.7 \mathrm{~kb}$ ), blunted, and subcloned into the $B g l I I$ site of the expression vector pSP64T (Krieg and Melton, 1984). These new constructs were linearized with either EcoRI (zfCx27.5) or XbaI (zfCx44.1 and $\mathrm{zfCx} 55.5$ ), and capped cRNAs were produced in vitro with SP6 RNA polymerase, using the mMessage mMachine kit (Ambion Inc. Austin, TX) according to the manufacturer's instructions. The purity and yield of transcribed cRNAs were determined by measuring absorbance at 260/280 $\mathrm{nm}$ and ranged between 1 and $1.4 \mu \mathrm{g} / \mathrm{ml}$.

Aliquots $(200 \mathrm{ng})$ of in vitro synthesized connexin cRNAs were translated $\left(1 \mathrm{hr}\right.$ at $\left.30^{\circ} \mathrm{C}\right)$ using a rabbit reticulocyte lysate system (Promega). Radioactive products $(1 / 10-1 / 20$ of the reaction volume) were diluted with gel sample buffer (25 mM Tris- $\mathrm{HCl}, \mathrm{pH}$ 6.8, $0.5 \%$ SDS, $0.1 \%$ $\beta$-mercaptoethanol, $17 \%$ glycerol, $0.01 \%$ bromophenol blue), separated by electrophoresis on an $11 \%$ SDS-polyacrylamide gel, and visualized by fluorography.

Preparation of Xenopus oocytes, microinjection, and metabolic labeling. Female Xenopus laevis were purchased from the colony of the Institut für Entwicklungsbiologie (Hamburg, Germany). After anesthesia with benzocaine, ovarian lobes were surgically removed and placed in Modified Barth's medium [(MB) $110 \mathrm{~mm} \mathrm{NaCl}, 1.3 \mathrm{~mm} \mathrm{KCl}, 3 \mathrm{~mm} \mathrm{NaHCO}, 19 \mathrm{~mm}$ HEPES, $\left.0.9 \mathrm{mM} \mathrm{MgSO}_{4}, 0.4 \mathrm{~mm} \mathrm{CaNO}_{3}, 2.5 \mathrm{mM} \mathrm{CaCl}_{2}, \mathrm{pH} 7.6\right]$ at $18^{\circ} \mathrm{C}$ overnight. Oocytes (stage V-VI) were defolliculated after collagenase digestion $(1 \mathrm{mg} / \mathrm{ml}$; collagenase $\mathrm{B})$ for $10 \mathrm{~min}$ at room temperature in $\mathrm{MB}$ without added calcium and processed for the paired oocyte expression assay essentially as previously described (Swenson et al., 1989; Ressot et al., 1998). For physiological analysis, manually defolliculated oocytes were injected with $40 \mathrm{nl}$ of either water or the appropriate dilutions of the various cRNAs (4-6 ng per cell). All cells, except when specified, received also an antisense oligonucleotide (2.5 ng per cell) corresponding to a portion of the coding sequence of Xenopus Cx38 to eliminate the possible contribution of endogenous intercellular channels to the measured conductance (Barrio et al., 1991; Bruzzone et al., 1993). After an overnight incubation at $18^{\circ} \mathrm{C}$, microinjected oocytes were immersed for a few minutes in hypertonic solution to strip the vitelline envelope (Methfessel et al., 1986), transferred to Petri dishes containing MB medium, and manually paired with the vegetal poles apposed.

Metabolic labeling of oocytes for biochemical analysis was performed by incubating overnight at $18^{\circ} \mathrm{C}$ oocytes microinjected with either water (control) or the various zebrafish connexin RNAs in MB supplemented with $0.5 \mathrm{mCi} / \mathrm{ml}\left[{ }^{35} \mathrm{~S}\right] \mathrm{methionine}$ (ICN Pharmaceuticals, Costa Mesa, CA). Cells were lysed in $5 \mathrm{~mm}$ Tris-HCl, $5 \mathrm{~mm}$ EDTA, 5 mM EGTA, pH 8.0, containing protease inhibitors (chymostatin, leupeptin, and pepstatin, $10 \mu \mathrm{g} / \mathrm{ml}$ each; Sigma), by repeated passages through a 22 gauge needle. Homogenates were then centrifuged at $3000 \times g$ for 5 min to remove yolk granules, and cleared supernatants were dried under vacuum and resuspended in gel sample buffer. Aliquots of lysates $(0.5-1$ oocyte equivalent per lane) were electrophoresed on $11 \%$ SDS gels and analyzed by fluorography as described above.

Electrophysiological measurements on oocytes. Intercellular communication was directly quantitated by double voltage clamp (Spray et al., 1981) $24-48 \mathrm{hr}$ after oocyte pairing. Current and voltage electrodes were pulled to a resistance of 1-2 M $\Omega$ with a vertical puller (Model PB-7, Narishige, Tokyo, Japan) and filled with a solution containing $3 \mathrm{M} \mathrm{KCl,} 10 \mathrm{~mm}$ EGTA, and $10 \mathrm{~mm}$ HEPES, $\mathrm{pH}$ 7.4. Voltage clamping of oocyte pairs was performed using two GeneClamp 500 amplifiers controlled by a PCcompatible computer through a Digidata 1200 interface; pCLAMP 6.0 software was used to program stimulus and data collection paradigms (all of the electrophysiological equipment was from Axon Instruments, Foster City, CA). Both cells of a pair were initially clamped at $-40 \mathrm{mV}$, close to their initial resting potential, which ranged between -30 and $-50 \mathrm{mV}$, to ensure zero transjunctional potential. For simple measurements of junctional conductance, alternating pulses of $\pm 10-20 \mathrm{mV}$ were imposed to one cell. The current delivered to the cell clamped at $-40 \mathrm{mV}$ during the voltage pulse is equal in magnitude to the junctional current and can be divided by the voltage to yield the value of junctional conductance. For analysis of voltage dependence, families of junctional currents were generated by applying transjunctional potentials of increasing amplitude and opposite polarity to one cell, in $10-20 \mathrm{mV}$ steps (over a range of \pm 100 $\mathrm{mV})$, whereas the second cell was clamped at a constant voltage $(-40 \mathrm{mV})$. Current outputs were filtered at $10 \mathrm{~Hz}$, and the sampling interval was 10 msec. Steady-state currents $\left(I_{\text {jss }}\right)$ were calculated using Clampfit functions in PCLAMP (Axon Instruments) at the end of the voltage steps, at which time they approached equilibrium. Steady-state conductance $\left(G_{\text {jss }}\right)$ values were normalized to their value at $\pm 10-20 \mathrm{mV}$ and plotted against the transjunctional potential. Data describing the macroscopic junctional conductance as a function of transjunctional voltage were analyzed using Microcal Origin 5.0 software (Microcal Software) and fit to a Boltzmann relation (Spray et al., 1981) of the form $G_{\text {jss }}=\left\{\left(G_{\text {jmax }}-G_{\text {jmin }}\right) /(1+\right.$ $\left.\exp \left[A\left(V_{\mathrm{j}}-V_{\mathrm{o}}\right)\right]\right\}+G_{\text {jmin }}$, where $G_{\text {jss }}$ is the steady-state junctional conductance, $G_{\text {max }}$ (normalized to unity) is the maximum conductance, $G_{\text {jmin }}$ is the normalized conductance at the largest values of transjunctional voltage $\left(V_{\mathrm{j}}\right)$, and $V_{\mathrm{o}}$ is the transjunctional voltage at which $G_{\mathrm{jss}}=\left(G_{\mathrm{jmax}}-\right.$ $\left.G_{\text {jin }}\right) / 2$. The constant $A(=n q / k T)$ represents the voltage sensitivity in terms of gating charge as the equivalent number $(n)$ of electron charges $(q)$ moving through the membrane, $k$ is the Boltzmann constant, and $T$ is the absolute temperature.

To ensure adequate control of voltage across the transjunctional membrane and avoid the risk of underestimating the actual junctional conductance at steady state (Wilders and Jongsma, 1992), only oocyte pairs exhibiting conductance $<6 \mu \mathrm{S}$ were selected for analysis of voltage dependence.

Functional expression and unitary conductance measurements in transiently transfected $N 2 A$ cells. Communication deficient N2A rat neuroblastoma cells (obtained from American Type Culture Collection, Manassas, VA) were transiently cotransfected with the PGM $3 Z$ plasmid harboring 2-4 $\mu \mathrm{g}$ of the zebrafish cDNAs ( $\mathrm{zfCx} 55.2$, zfCx44.1, and $\mathrm{zfCx} 27.5$, respectively) and the EGFP vector (Clontech). All cell types were transfected using LIPOfectamine Plus (Life Technologies) after the procedure outlined by the manufacturer. Cell cultures were maintained in a $37^{\circ} \mathrm{C}$ incubator in a moist $5 \% \mathrm{CO}_{2} / 95 \%$ air environment. The day after transfection, cells were plated at low density onto $1 \mathrm{~cm}$ diameter glass coverslips; 8-24 hr later coverslips were transferred to the stage of a Nikon Diaphot microscope and bathed in an external solution containing (in $\mathrm{mM}$ ): $\mathrm{NaCl}$ $140, \mathrm{CsCl} 2, \mathrm{CaCl}_{2} 2, \mathrm{MgCl}_{2}$ 1, $\mathrm{HEPES} 5, \mathrm{KCl} 4$, dextrose 5, pyruvate 2, $\mathrm{BaCl}_{2} 1$, pH 7.2. Junctional conductance was measured between cell pairs using the dual whole-cell voltage-clamp technique with Axopatch $1 \mathrm{C}$ or $1 \mathrm{D}$ patch-clamp amplifiers (Axon Instruments). Only those cell pairs that showed EGFP fluorescence, indicative of successful transfection with the connexin plamsid, were clamped. Each cell of a cell pair was voltageclamped with patch pipettes pulled on a Flaming/Brown Micropipette puller (model P-87, Sutter Instruments, Novato, CA). The patch electrodes had resistances of 4-7 M $\Omega$ when filled with an internal solution containing (in mmol/1): $\mathrm{CsCl} 130$, EGTA $10, \mathrm{CaCl}_{2} 0.5, \mathrm{MgATP} 3, \mathrm{Na}_{2}$ ATP 2, HEPES 10, pH 7.2. All experiments were performed at room temperature. The osmolarities of external and internal solutions, measured using the freezing point method (Microosmette, World Precision Instruments, Sarasota, FL) were $285 \pm 5 \mathrm{mOsm}$. Macroscopic and single-channel recordings were filtered at $0.1-1 \mathrm{kHz}$ and sampled at $1-5 \mathrm{kHz}$. Each cell of a pair was initially held at a common holding potential of $0 \mathrm{mV}$. Thereafter, voltage pulses of variable duration and amplitude were applied to one cell to establish a transjunctional voltage gradient $\left(V_{\mathrm{j}}\right)$, and the instantaneous and steady-state junctional current were measured in the second cell (held at 0 $\mathrm{mV})$. Data acquisition and processing were performed as described above (for the oocyte experiments). Unitary current events were recognized as simultaneously occurring equal-sized events of opposite polarity in the current recording of each cell; these events were measured from freshly split cell pairs and in weakly fluorescent cell pairs in which the level of coupling was low. All point amplitude histograms of data were constructed for each experiment and fit to Gaussian functions to determine the mean and variance of the baseline and open channel current. Unitary conductances were measured by fitting a linear function to the single-channel current-voltage relation.

\section{RESULTS}

\section{Cloning of the fish ortholog of Cx43 and three further members of the connexin family}

To clone neural connexins from the retina, we started with an enriched preparation of horizontal cells. After papain digestion and mechanical trituration followed by differential centrifugation in a Ficoll gradient, we obtained a fraction of enriched horizontal cells, which represented $\sim 70 \%$ of the total population. Contaminating cells consisted of amacrine cells, photoreceptors, bipolar cells, and Müller cells. Degenerate oligonucleotide primers were selected for RT-PCR (Haefliger et al., 1992). Three consensus degenerate oligonucleotides corresponding to highly conserved external loop sites of rodent connexins were used for RT-PCR amplification. The amplified fragments corresponded to the second and third transmembrane domains (M2 and M3), which are separated by a cytoplasmic loop of variable length.

Amplification with degenerate primers yielded two bands: a broad band with a size between 350 and 480 bp as evidenced by agarose gel electrophoresis and a second band of $\sim 600$ bp. Subcloning of the extracted broad band and Southern hybridization with probes derived from mouse connexins resulted in the detection of different fragments from which three that hybridized with the mouse cDNAs fragments coding for Cx43, Cx26, and Cx50 were further characterized (see Materials and Methods). These fish fragments are indicated as frag43, frag26, and frag50. Frag43 
revealed an $\sim 80 \%$ amino acid homology to rat $\mathrm{Cx} 43$ and $99.2 \%$ homology to zfCx43 [zfCx43.3; GenBank accession number AF035481, submitted by Finis et al. (1998)]. Frag26 and frag50 exhibited only partial homology to the mouse probes used for Southern hybridization.

To complete the carpCx43 cDNA, we used frag43 as a template for RACE extension with carp retina RNA. RACE extension yielded a complete open reading frame of carpCx43, which showed an overall identity of its amino acid sequence of $\sim 90 \%$ with rat Cx43. The cDNA predicted a protein with a molecular mass of 43,277 Da. Alignment of the predicted carp connexin amino acid with rat and zfCx43 clearly identifies carpCx43 as the fish ortholog of the mammalian $\mathrm{Cx} 43$ (data not shown; accession number of the carp Cx43 available under GenBank accession number AY008286).

The carpCx43 cDNA obtained by RACE extension was further used to screen a $\lambda$ gt11 cDNA library prepared from zebrafish retina. In addition to the $\mathrm{zfCx} 43 \mathrm{cDNA}$ clone, we obtained four clones with variable length (between 2.5 and $5.5 \mathrm{~kb}$ ). All four clones were subcloned into the pBluescript SK-vector and sequenced. Sequencing of the $5.5 \mathrm{~kb}$ clone revealed an incomplete $3^{\prime}$-end 1145 bp clone that by sequence analysis at the DNA level revealed homology to the connexin gene family. Completion of the 1145 fragment was performed by high-stringency screening of a genomic zebrafish library. One of seven positive clones was used for further analysis. Subcloning of the complete insert and sequencing indicated that this clone contained the entire coding region, which had a total length of $1176 \mathrm{bp}$. The predicted molecular mass of this connexin according to the deduced amino acid sequence is 44,170 Da. According to the current nomenclature, which identifies each connexin by species of origin and predicted molecular mass in kilodaltons and to avoid confusion with the published zebrafish Cx44.2 [GenBank accession number AF072451; submitted by Duga et al. (1999)], this connexin is designated as zfCx44.1. Interestingly, zfCx44.1 reveals the highest homology score with human and mouse lens fiber Cx50 (73.9\%). Even in the cytoplasmic and $\mathrm{C}$-terminal sequences, domains that are the least homologous among the connexin family, one can find small amino acid sequences that show conservation exclusively between $\mathrm{zfCx} 44.1$ and Cx50: for example, residues 145-152 (KKFRLEGT) in the cytoplasmic hinge site and residues 266-274 (SSIQKAKGY) in the middle of the cytoplasmic tail. The most significant divergence occurs at the $\mathrm{C}$ terminus, which is $\sim 48$ amino acids shorter than that of $\mathrm{Cx} 50$, accounting for most of the $5.8 \mathrm{kDa}$ difference in molecular mass between the two connexins (Fig. 1A). Little homology is found between the published zebrafish $\mathrm{Cx} 44.2$ and our zfCx44.1 (44.9\%).

We then used frag26 and frag50 and went through the same runs of genomic cloning as indicated for $\mathrm{zfCx} 44.1$. Frag26 yielded nine positive clones, of which one (clone 9) contained an open reading frame of $723 \mathrm{bp}$ encoding a 240 amino acid protein. The predicted molecular mass is $27,516 \mathrm{Da}$. Frag50 yielded nine positive clones. Three of these clones were sequenced and revealed identical open reading frames of 1,497 bp encoding a 498 amino acid protein with a predicted molecular mass of $55,475 \mathrm{Da}$. In keeping with the traditional nomenclature, these connexins are referred to as zfCx27.5 and zfCx55.5.

Alignments of the amino acid sequences of the three novel zebrafish connexins with mammalian connexins that showed the highest homology scores (Fig. $1 A-C$ ) show a remarkable conservation of amino acids in the transmembrane domains with matching

(M1-M4) are outlined, and highly conserved amino acids are highlighted in black. Homologous stretches including conservative exchanges are indicated by the shaded boxes on top of the alignments. A, Alignment of $\mathrm{zfCx} 44.1$ with the mouse $\mathrm{Cx} 50$ to which the fish connexin shows an overall homology of $71 \%$. B. Comparative alignments of $\mathrm{zfCx} 27.5$ with rat $\mathrm{Cx} 32$ and $\mathrm{Cx} 26 . \mathrm{ZfCx} 27.5$ is different form both connexins of the $\beta$-group, in particular at the $\mathrm{C}$ terminus. $C$, Alignment of $\mathrm{zfCx} 55.5$ with mouse $\mathrm{Cx} 57$. The overall homology score is $\sim 55.2 \%$, indicating that both connexins represent different genes.
A

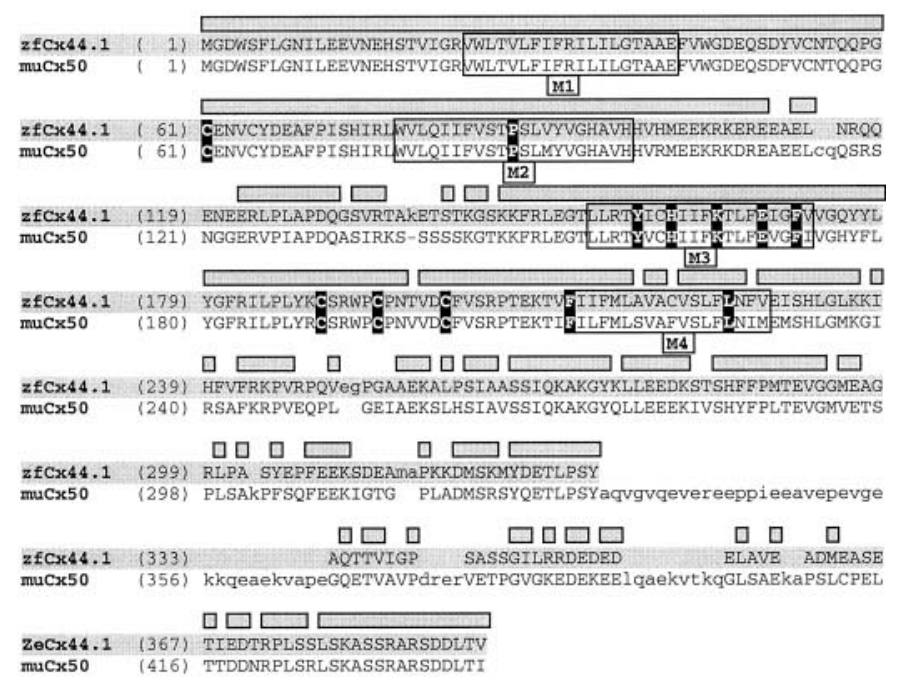

B
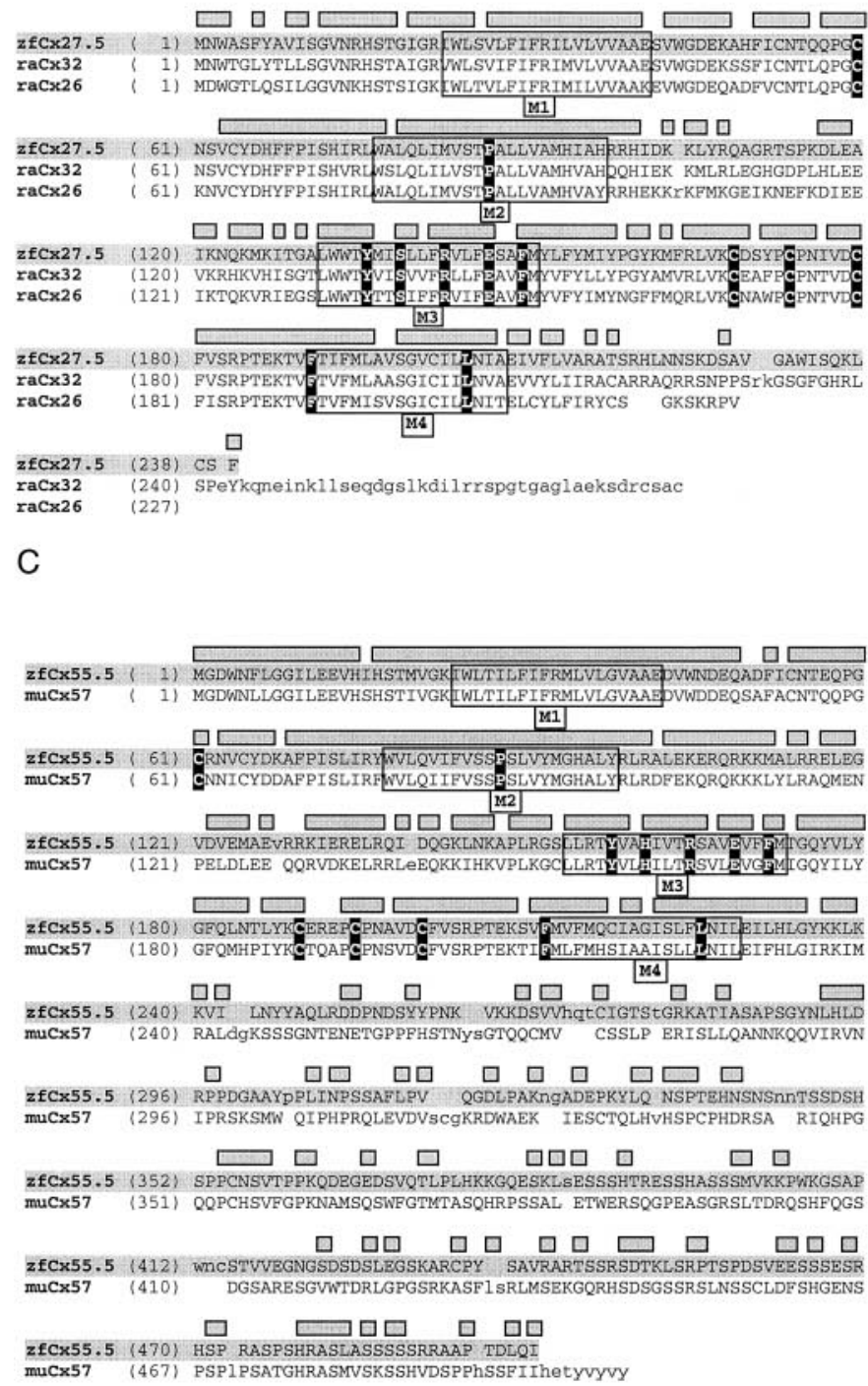

Figure 1. Comparison of the novel zebrafish connexins (shaded in gray) with the most homologous rodent connexins. The alignments were created with the mAlign software at the GeneBee-services website (http://www. genebee.msu.su/services/malign_reduced.html); transmembrane domains 


\section{A}

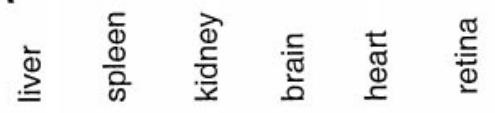

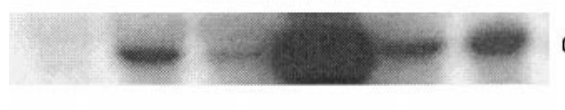

carpCx43
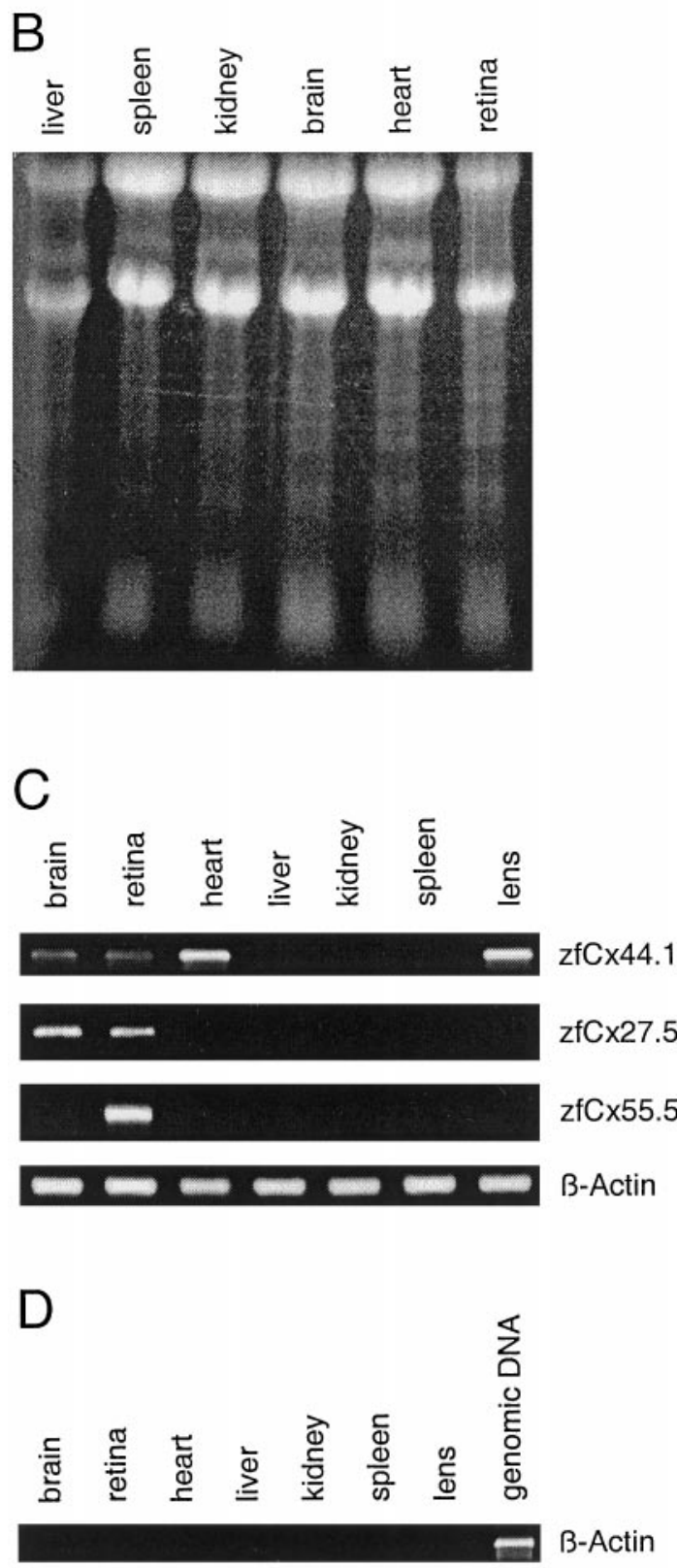

Figure 2. Multiple-tissue Northern blots and RT-PCRs of fish connexins. $A$, Northern blot of carpC $x 43$ mRNA. CarpCx 43 mRNA is highest in brain and retina, whereas liver reveals no detectable levels. $B$, Ethidium bromidestained agarose gel of $A$ that shows comparative loading of mRNA (18S and $28 \mathrm{~S}$ band). $C$, Multiple-tissue RT-PCR of the three zebrafish connexins (ethidium bromide-stained agarose gels). $\mathrm{zfCx} 44.1$ is less abundant in brain and retina, with higher levels in lens and heart. zfCx27.5 shows tissuerestricted expression in brain and retina, whereas zfCx55.5 is exclusively expressed in the retina. All cDNA preparations were controlled by PCR using primers specific for $\beta$-actin. $D$, PCR control (with $\beta$-actin primers) omitting reverse transcription. No amplification is evident with the exception of the genomic DNA, indicative of lack of genomic DNA contamination in the mRNA samples.

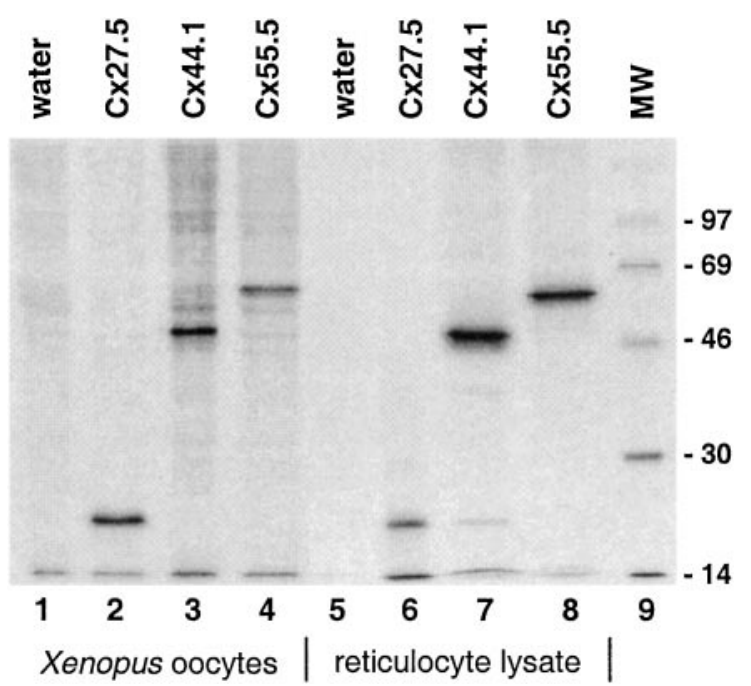

Figure 3. Translation of zebrafish connexin cRNAs in microinjected Xenopus oocytes and reticulocyte lysate. Experimental conditions are indicated on top of each lane. Xenopus oocytes were injected with $40 \mathrm{nl}$ of either water or cRNAs $(\sim 40-60 \mathrm{ng}$ per cell $)$ coding for retinal zebrafish connexins and incubated in the presence of $\left[{ }^{35} \mathrm{~S}\right] \mathrm{methionine}(0.5 \mathrm{mCi} / \mathrm{ml})$. Translated products and labeled proteins from oocyte homogenates were separated on a 13\% SDS-polyacrylamide gel and detected by fluorography. The migration of protein standards is shown in lane 5 with their molecular mass (in kilodaltons) indicated on the right edge of the gel.

of the highly conserved proline in the second transmembrane domain, and four charged or polar residues within the third transmembrane region that have been postulated to represent the putative amphipathic strand that lines the junctional channel (Milks et al., 1988). Also, the four cysteine residues within the two extracellular loops (EL1 and EL2) match at exactly the same positions as indicated for the other connexins. The cytoplasmic hinge regions and the C-terminal tails are least well conserved.

In detail, zfCx27.5 shows overall homology (i.e., identity plus conservative amino acid replacements) of $\sim 80.6 \%$ to rat Cx26. However, minimal sequence identity is $<53.8 \%$ in the putative cytoplasmic loop, and the putative $\mathrm{C}$-terminal domain is extended

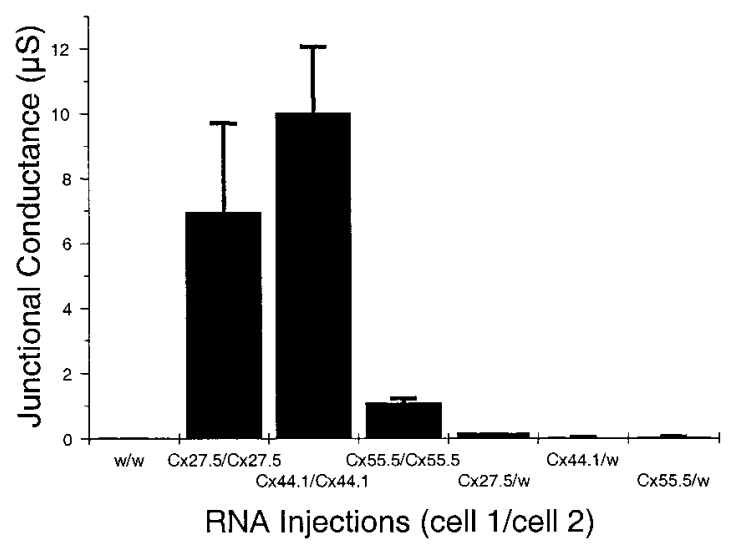

Figure 4. Expression of zebrafish connexins induces the formation of homotypic intercellular channels. Oocytes pretreated with an oligonucleotide antisense to a sequence within the coding region of Xenopus $\mathrm{C} \times 38$ were injected with either connexin cRNAs or water $(w)$ and paired for $24-48 \mathrm{hr}$ before measuring junctional conductance by dual voltage clamp. Cells received similar amounts of connexin cRNAs $(\sim 40-60 \mathrm{ng}$ per cell). To exclude the possibility that zebrafish connexins could interact with endogenous Xenopus Cx38, we constructed heterotypic pairs between oocytes injected with $\mathrm{zfCx} 27.5, \mathrm{zfCx} 44.1$, or $\mathrm{zfCx} 55.5$ and mock-treated cells, which did not receive antisense DNA oligonucleotides. These heterotypic $\mathrm{Cx} /$ mock pairs showed conductance levels $(0.05 \pm 0.02 \mu \mathrm{S}$ for $\mathrm{zfCx} 27.5 / \mathrm{mock}$; $0.03 \pm 0.01 \mu \mathrm{S}$ for $\mathrm{zfCx} 44.1 / \mathrm{mock} ; 0.04 \pm 0.01 \mu \mathrm{S}$ for $\mathrm{zfCx} 55.5 / \mathrm{mock})$ not differing from those of control, antisense-treated pairs $(w / w)$. Values are the means \pm SEM of $6-13$ oocyte pairs. 
A

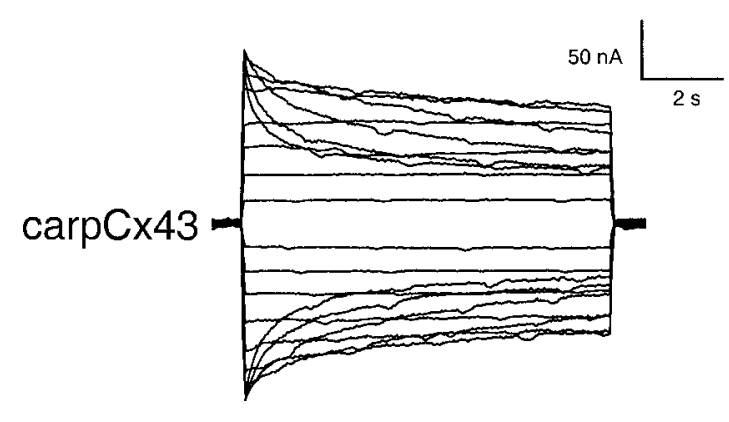

B carpCx43

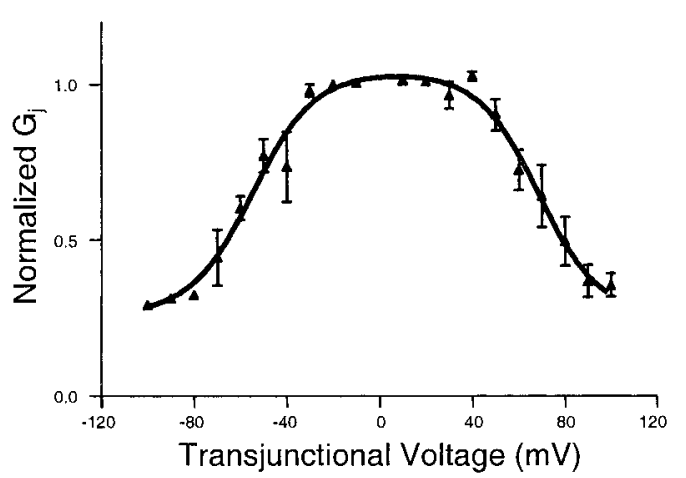

Figure 5. Carp Cx43 forms functional gap junctions in Xenopus oocytes $(A, B)$. A representative current trace is shown for a homotypic carpCx43 junction with a conductance of $\sim 2 \mu \mathrm{S}$. Currents were elicited by application of transjunctional voltage using standard dual-cell, two-electrode voltage-clamp techniques. Paired cells were voltage-clamped at $-40 \mathrm{mV}$; one cell was then pulsed to voltages between $+60 \mathrm{mV}$ and $-140 \mathrm{mV}$ in $10 \mathrm{mV}$ increments. Clamping currents in the apposed cell reflect the junctional current. The time-dependent reduction in junctional current in response to voltage is very similar to the voltage-dependent closure of mammalian orthologs of $\mathrm{Cx} 43$. B. Normalized conductance-voltage relationship for carpCx43. Data were obtained from three experiments in which $G_{\mathrm{j}}$ was $<2 \mu \mathrm{S}$. Data were fit with a Boltzmann equation as described in Materials and Methods.

by 22 amino acids with an overall homology of only $19.5 \%$ to rat Cx26 (Fig. 1B).

There is less correspondence between $\mathrm{zfCx} 55.5$ and other vertebrate connexins. Score homology to mouse Cx57 (Manthey et al., 1999) is $55.2 \%$ and to mouse Cx50 is $46 \%$, but there is considerable variation at the putative cytoplasmic loop and the $\mathrm{C}$ terminus (Fig. $1 C$ ). Sequences of the zebrafish connexins are available under GenBank accession numbers AF304048 (zfCx55.5), AF304049 (zfCx27.5), and AF304050 (zfCx44.1).

\section{Tissue expression: Northern blots, and multiple tissue RT-PCR}

The expression of the three zebrafish connexins and the carpCx43 was studied by Northern blot analysis of total RNA samples. Probes were selected on the basis of their maximal divergence from the coding sequences of known connexins (see Materials and Methods).

The carpCx43 probe labeled a strong $3.0 \mathrm{~kb}$ transcript in most tissues studied (Fig. 2A,B). The highest concentration of the transcript was detected in carp brain, where the signal was even more pronounced than in retina and heart under standardized probing conditions (Fig. 2A,B). In contrast, zfCx27.5, zfCx44.1, and zfCx55.5 showed no positive signals on Northern blots of RNAs isolated from several organs, including retina and lens, indicative of low abundance of these connexins in the eye. Thus, for the detection of tissue expression of the three zebrafish connexins we used multiple tissue RT-PCR.

Multiple tissue RT-PCR from seven tissues with specific primer sets including nested primers indicated a differential expression of the three zebrafish connexins. ZfCx44.1 was expressed in several tissues (Fig. $2 C$ ), with the strongest amplification in heart and lens and lower abundance in brain and retina. ZfCx27.5 and zfCx55.5 showed a more restricted expression pattern. ZfCx27.5 showed amplification in brain and retina, whereas zfCx55.5 was exclusively detectable in retina (Fig. 2C). Both connexins can therefore be regarded as neural restricted connexins. Control reactions in which the reverse transcriptase was omitted yielded no amplicons (Fig. 2D).

\section{Functional expression}

A reliable assay to evaluate the functional activity of connexins is the paired Xenopus oocyte expression system (Dahl et al., 1987). Thus, connexin constructs subcloned into pSP64T were used as templates in transcription reactions to produce cRNAs for the paired oocyte assay. The translational competence of transcripts was initially examined in a rabbit reticulocyte lysate system supplemented with $\left[{ }^{35} \mathrm{~S}\right]$ methionine. Labeled proteins were separated by SDS-gel electrophoresis. Translation reactions that received connexin cRNAs (200 ng each) directed the synthesis of a major polypeptide band, whose electrophoretic mobility was in agreement with the molecular weight deduced from the amino acid sequence (Fig. 3, lanes 6-8). As is the case with rodent $\mathrm{Cx} 26$, which migrates as a $\sim 21 \mathrm{kDa}$ protein (Nicholson et al., 1987), zfCx27.5 exhibited faster gel mobility. Similar amounts of connexin cRNAs (4-6 ng per cell) were subsequently injected into single oocytes to determine translatability in vivo. Injection of $\mathrm{zfCx} 27.5$, $\mathrm{zfCx} 44.1$, or zfCx55.5 cRNA resulted in the appearance of novel bands with the expected electrophoretic mobilities (Fig. 3, lanes 2-4) that were easily identified over the pattern of labeled endogenous proteins (lane 1). CarpCx43 was not subjected to in vitro translation because translational competence of the mammalian orthologs has frequently been demonstrated (Nicholson et al., 1993). Together, these experiments demonstrate that oocytes can support the biosynthesis of the novel retinal zebrafish connexins and indicate that similar amounts of injected cRNAs produce comparable amounts of labeled proteins.

Manual pairing of devitellinized oocytes injected with cRNAs for carpCx43, $\mathrm{zfCx} 27.5, \mathrm{zfCx} 44.1$, and $\mathrm{zfCx} 55.5$ resulted in the efficient assembly of homotypic channels and induced conductance levels comparable with those developed by pairs receiving similar amounts of cRNAs encoding mammalian connexins (Dahl et al., 1987; Barrio et al., 1991; Nicholson et al., 1993; White and Bruzzone, 1996). To minimize the contribution of endogenous connexins to the recorded conductance, all oocytes were treated with antisense oligonucleotides against Xenopus Cx38 (Barrio et al., 1991; Bruzzone et al., 1993), so that the background level of communication of water-injected control pairs $(0.02 \pm 0.005 \mu \mathrm{S}$, $n=13$ ) was at least 50 -fold lower than that measured with pairs expressing retinal connexins (Fig. 4). In addition, we examined the possibility that zebrafish connexins could interact with endogenous Xenopus $\mathrm{Cx} 38$ by constructing heterotypic pairs between oocytes injected with zfCx27.5, zfCx44.1, or zfCx55.5 and mock-treated oocytes, which did not receive antisense DNA oligonucleotides. These heterotypic $\mathrm{Cx} /$ mock pairs showed conductance levels not differing from those of control, antisense-treated pairs (Fig. 4).

Homotypically paired oocytes injected with approximately the same amounts of cRNA (4-6 ng per cell), however, revealed differences in the functional activity of retinal zebrafish connexins. The lowest values of junctional conductance were obtained by homotypic injection of $\mathrm{Cx} 55.5$, whereas pairs expressing $\mathrm{Cx} 44.1$ yielded the highest values (Fig. 4). Such differences in macroscopic levels of conductance between the pairs of connexin-injected oocytes are in keeping with unitary conductance values observed in N2A cells transfected with these connexins (see below) and with previous reports that unitary junctional conductances of channels 

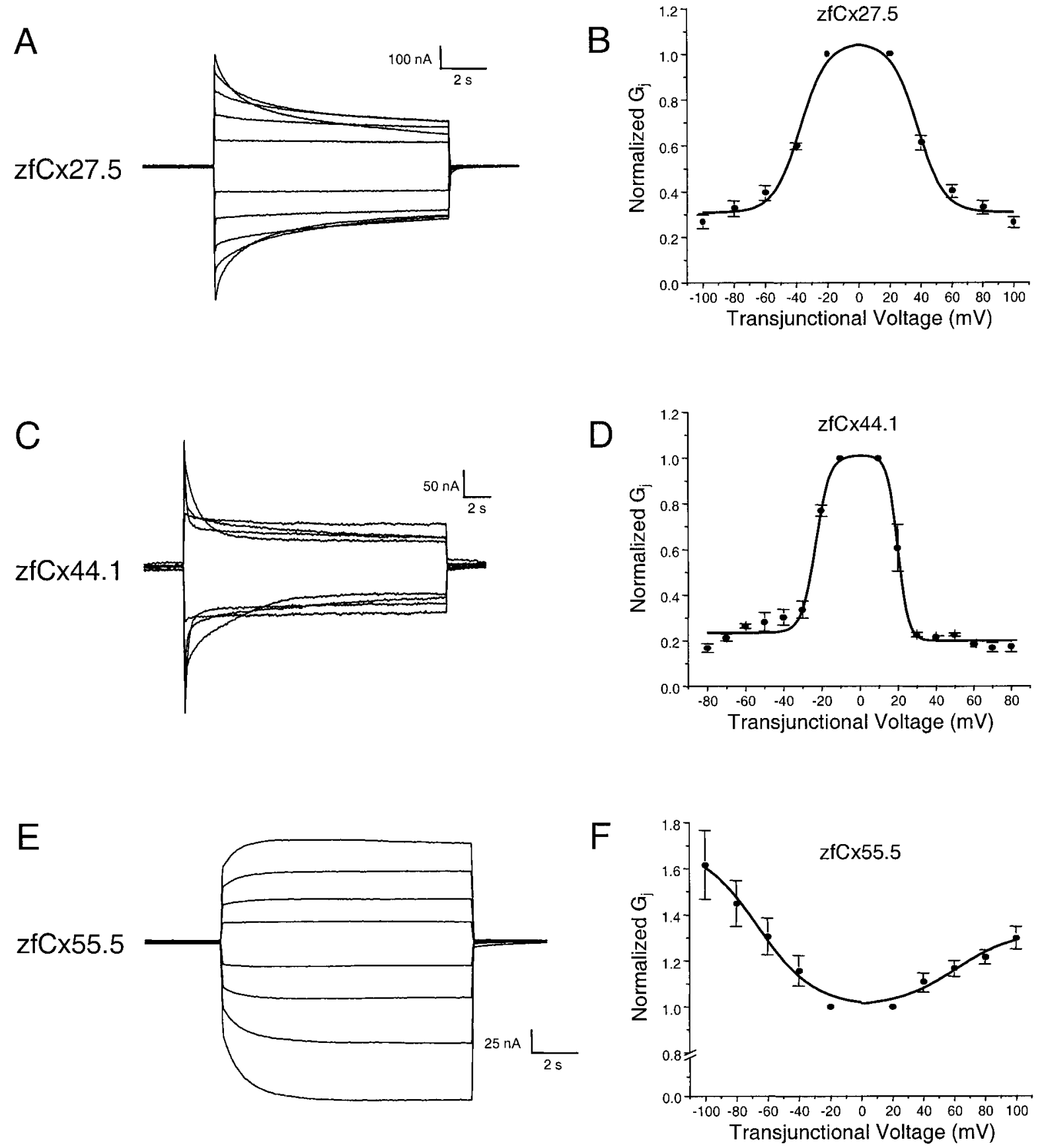

Figure 6. Voltage-gating behavior of gap junction channels formed by zfCx27.5 $(A, B), \mathrm{zfCx} 44.1(C, D)$, and zfCx55.5 (E, F). Traces $(A, C, E)$ show the time-dependent decay of junctional currents $\left(I_{\mathrm{j}}\right)$ induced by transjunctional voltage $\left(V_{\mathrm{j}}\right)$ steps applied in $10-20 \mathrm{mV}$ increments. Plots $(B, D, F)$ describe the relationship of $V_{\mathrm{j}}$ to steady-state junctional conductance $\left(G_{\mathrm{jss}}\right)$, normalized to the values obtained at $\pm 10 \mathrm{mV}$. For both zfCx27.5 $(A, B)$ and $\mathrm{zfCx} 44.1$ $(C, D), V_{\mathrm{j}}$ induced an almost symmetrical channel closure, with a much lower threshold and faster time course in the case of zfCx44.1. In contrast, zfCx 55.5 $(E, F)$ displayed an opposite voltage-gating behavior. Results are shown as mean \pm SEM of five to eight oocyte pairs; their conductance at the beginning of the experiment did not exceed $6 \mu \mathrm{S}$ for a $V_{\mathrm{j}}$ of $\pm 10 \mathrm{mV}$. The curves represent the best fits to Boltzmann equations, the parameters of which are given in Table 1.

formed by different connexins can differ by an order of magnitude (Spray, 1996; Veenstra, 1996).

The analysis of junctional currents demonstrated some specific features with respect to their voltage dependence. Voltage steps of positive and negative polarities were imposed in $10 \mathrm{mV}$ increments from a holding potential of $40 \mathrm{mV}$ and lasted $22.5 \mathrm{sec}$ to allow currents to approach equilibrium values. Junctional currents of carpCx43 were voltage dependent, closing in response to the application of transjunctional voltage $\left(V_{\mathrm{j}}\right)$ (Fig. $\left.5 A, B\right)$. The Boltzmann equation yielded values of $V_{\mathrm{o}}$ and $G_{\text {jmin }}$ similar to those of rat Cx43 (White et al., 1994) and zfCx43.3 (Wagner et al., 1998) expressed in Xenopus oocytes or transfected N2A cells $\left(V_{\mathrm{o}}=-55\right.$
$\left.\mathrm{mV}, \mathrm{G}_{\mathrm{jmin}}=0.26\right)$. A slight asymmetry with respect to the pulsed and clamped cells was evident and similar to that reported for rat Cx43 (White et al., 1994) but with opposite polarity. This asymmetry with respect to voltage sensitivity is not likely to be of physiological significance but may represent an effect of voltage (membrane potential) on the number of functional channels, as reported for rat $\mathrm{Cx} 43$ (Banach and Weingart, 1996). Taken together, these functional data strongly support the notion that carpCx43 represents the fish homolog of mammalian $\mathrm{Cx} 43$.

Figure 6 shows typical families of junctional currents and plots of normalized conductance $\left(G_{\mathrm{j}}\right)$ versus transjunctional potentials of the new zebrafish connexins. Junctional currents of zfCx27.5 chan- 
Table 1. Comparison of Boltzmann parameters of gap junction channels composed of retinal zebrafish connexins

\begin{tabular}{lllllll} 
Channel & $V_{\mathrm{j}}$ & $A$ & $n$ & $V_{0}$ & $G_{\text {jmax }}$ & $G_{\text {jmin }}$ \\
\hline $\mathrm{Cx} 27.5 / \mathrm{Cx} 27.5$ & + & 0.12 & 3.0 & 38 & 1.00 & 0.31 \\
$\mathrm{C} 27.5 / \mathrm{Cx} 27.5$ & - & 0.12 & 3.0 & 37 & 1.00 & 0.31 \\
$\mathrm{C} \times 44.2 / \mathrm{Cx} 44.2$ & + & 0.37 & 9.3 & 20 & 1.00 & 0.20 \\
$\mathrm{Cx} 44.2 / \mathrm{Cx} 44.2$ & - & 0.27 & 6.8 & 23 & 1.00 & 0.23 \\
$\mathrm{Cx} 55.5 / \mathrm{Cx} 55.5$ & + & 0.05 & 1.3 & 61 & 1.00 & 1.33 \\
$\mathrm{Cx} 55.5 / \mathrm{Cx} 55.5$ & - & 0.06 & 1.4 & 66 & 1.00 & 1.70
\end{tabular}

Junctional conductance $\left(G_{\mathrm{j}}\right)$ developed between pairs of Xenopus oocytes expressing different constructs was measured by dual voltage clamp in response to increasing transjunctional potentials $\left(V_{\mathrm{j}}\right)$ of opposite polarity and normalized to the conductance measured at a $V_{\mathrm{j}}$ of $\pm 10 \mathrm{mV}$ ( $G_{\mathrm{jmax}}$, set as unity) as described in Materials and Methods. Data were fit to a Boltzmann equation of the form given in the text. $G_{\text {jmin }}$ is the minimum conductance value as estimated from the Boltzmann fit, and $V_{0}$ is the voltage at which half-maximal decrease of $G_{\mathrm{j}}$ is measured. In the case of $\mathrm{zfCx} 55.5$, an opposite voltage gating was observed, implying that $G_{\text {jmin }}$ is the maximum conductance value, and $V_{0}$ is the voltage at which half-maximal increase of $G_{\mathrm{j}}$ is measured. The cooperativity constant $(A)$, reflecting the voltage sensitivity of the channel, can also be expressed as the equivalent number $(n)$ of electron charges moving through the transjunctional field. The plus and minus signs for $V_{\mathrm{j}}$ refer to the polarity of the voltage steps. These parameters were derived from oocyte pairs the mean $G_{\mathrm{j}}$ of which was $2.4 \pm 0.5 \mu \mathrm{S}(n=8)$ for $\mathrm{zfCx} 27.5,3.7 \pm 1.0 \mu \mathrm{S}(n=5)$ for $\mathrm{zfCx} 44.2$, and $1.1 \pm 0.2$ $(n=8)$ for and $\mathrm{zfCx} 55.5$. nels decreased symmetrically with a slow time course, starting at transjunctional potentials greater than $\pm 20 \mathrm{mV}$ (Fig. $6 \mathrm{~A}$ ), and plots of normalized conductance versus transjunctional potentials could be fitted by one Boltzmann relation for both polarities (Fig. 6B, Table 1). In contrast, zfCx44.1 exhibited a much greater sensitivity to voltage-induced closure with currents decaying rapidly for transjunctional potentials $>10 \mathrm{mV}$ (Fig. 6C,D). The entire transition from maximal to minimal conductance was achieved with transjunctional potentials over the range of $10-30 \mathrm{mV}$ (and -10 to -30 $\mathrm{mV}$ ), indicating a very large equivalent gating charge (Table 1). Thus, the voltage gating behavior of $\mathrm{zfCx} 44.1$ is similar to that previously reported for mouse Cx50 (White et al., 1994; Srinivas et al., 1999a). Fitting the data of normalized steady-state conductance from three pairs to a Boltzmann equation of the form given in Materials and Methods revealed a slightly asymmetrical behavior (Table 1).

Most interestingly, zfCx55.5 channels showed a voltage dependence in response to steps of either polarity that was opposite to that displayed by all other connexins (Fig. $6 E, F$ ). To our surprise, we did not observe any time-dependent decay of junctional currents even with the largest transjunctional voltage steps applied $( \pm 100$ $\mathrm{mV}$ ), but instead, the amplitude of currents recorded in $\mathrm{zfCx} 55.5$ homotypic pairs reflected a substantial voltage-induced channel
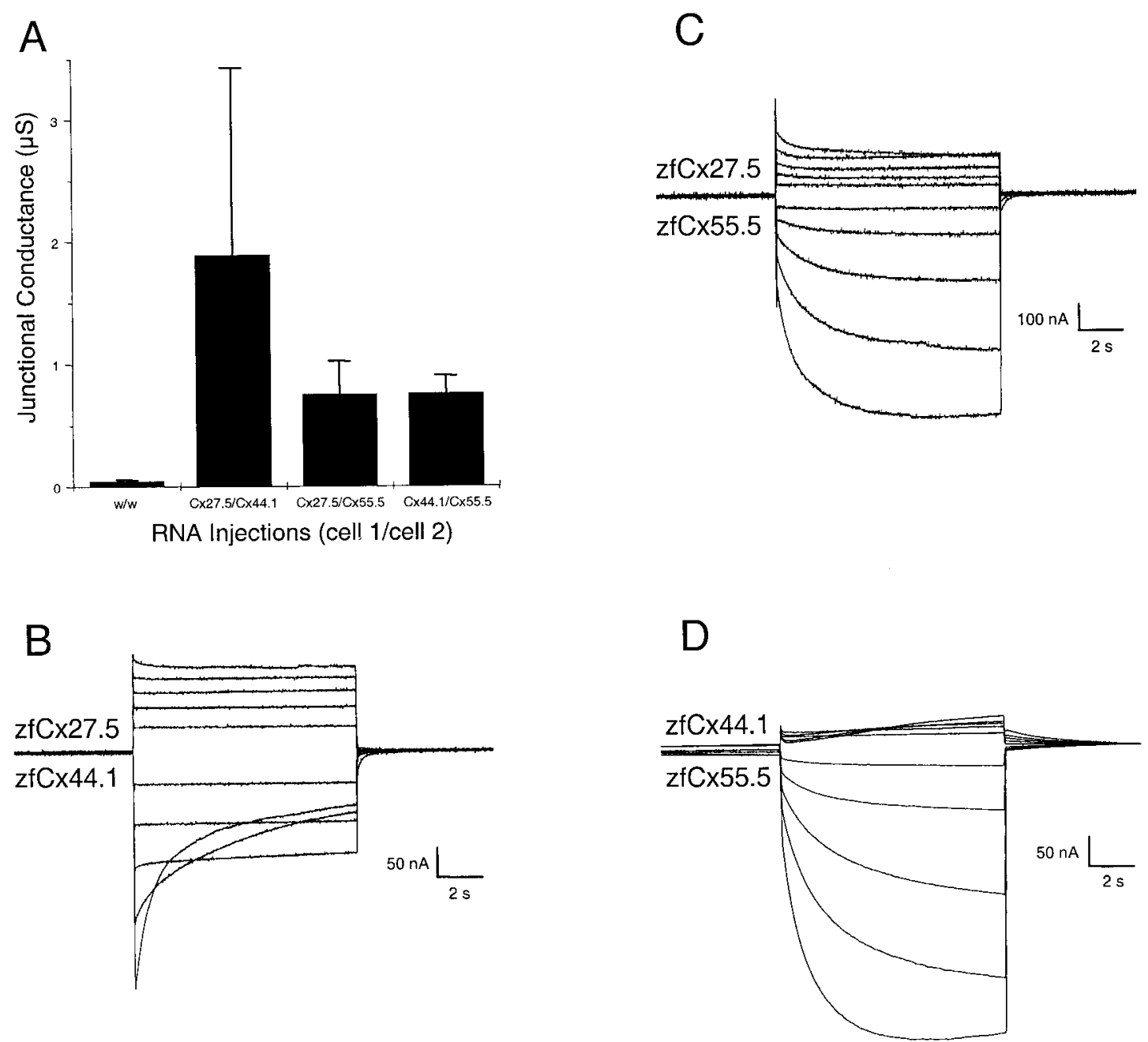

Figure 7. ZfCx27.5, zfCx44.1, and zfCx55.5 are compatible connexins that can assemble heterotypic channels. All oocytes received antisense oligonucleotides and then were injected with either water or similar amounts of connexin cRNAs ( $\sim 40-60$ ng per cell). Cells were manually paired and incubated at $18^{\circ} \mathrm{C}$ for $24-48 \mathrm{hr}$ before measurements of junctional conductance were performed using a dual voltage clamp. $A$, All heterotypic combinations resulted in the development of junctional conductances, which greatly exceeded those of control pairs (w/w, $0.05 \pm 0.01 \mu \mathrm{S})$ shown as means \pm SEM of the four pairs (for experimental procedure see Fig. 4). $B-D$, Families of traces were recorded in response to transjunctional voltage $\left(V_{\mathrm{j}}\right)$ steps applied in $20 \mathrm{mV}$ increments, as described in Materials and Methods. An obvious asymmetry of the voltage-gating behavior was observed in all heterotypic combinations. Channels comprising zfCx55.5 $(C, D)$ displayed a marked rectification, which is strongest in the zfCx44.1/zfCx55.5 configuration $(D)$. 
A
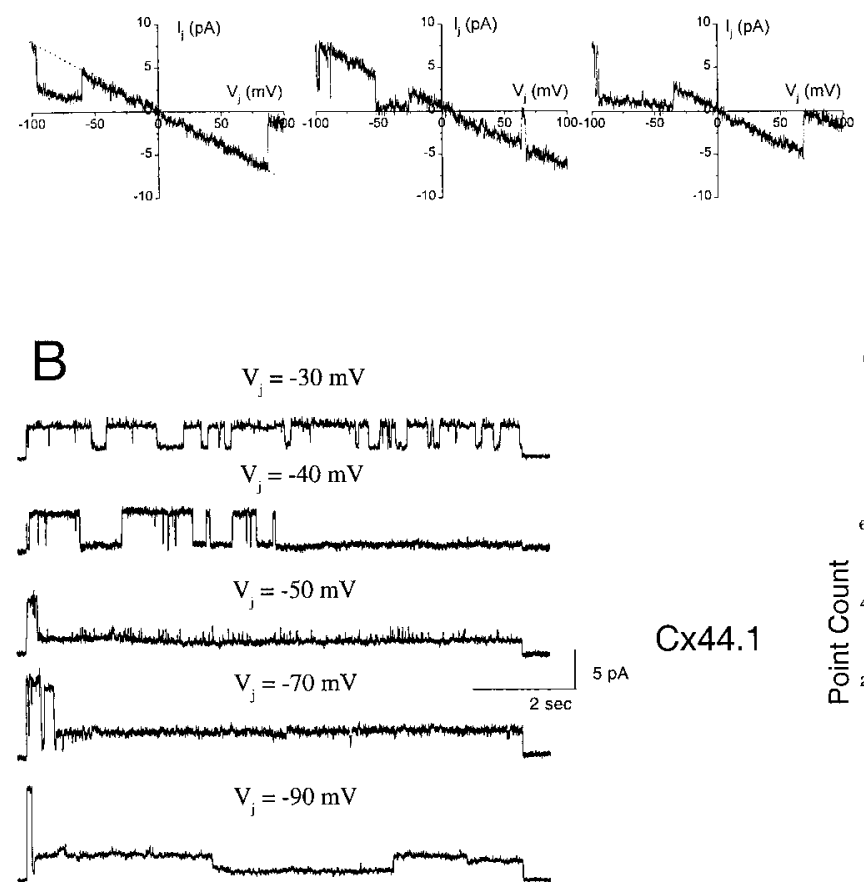

Cx44.1

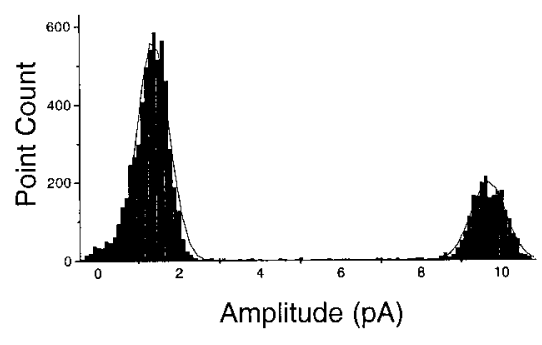

Figure 8. Single-channel properties of gap junctions formed of $\mathrm{zfCx} 27.5$ $(A), \mathrm{zfCx} 44.1(B)$, and zfCx55.5 $(C)$ as measured in transfected N2A cell pairs exhibiting a single active channel. $A$, In ramp protocols sweeping from +100 to $-100 \mathrm{mV}$ during a 15 sec period, zfCx27.5 channels displayed a main state unitary conductance of $\sim 78 \mathrm{pS}$ (dotted line in first trace) and a substate conductance (evident at both high and low $V_{\mathrm{j}}$ values in the first and last traces) of $\sim 15-20 \mathrm{pS}$. The first and last ramps are from the same cell pair, whereas the middle ramp recording is from another pair. $B$, Single-channel properties of $\mathrm{zfCx} 44.1$. The top series of traces are recordings obtained in response to the transjunctional voltages $\left(V_{\mathrm{j}}\right)$ indicated, which were applied to the other cell of the pair. Note that time residing in the fully open state is decreased as $V_{\mathrm{j}}$ is increased and that this decrease in open probability of the main state is associated with increased occupancy of the subconductance state. $C$, All-point histogram representing the response to $-40 \mathrm{mV} V_{\mathrm{j}}$. Peaks in the histogram correspond to $0,1.36$, and $9.6 \mathrm{pA}$, from which substate and main state conductances of 34 and 260 pS were calculated. $D$, Unitary conductance properties of zfCx55.5. For pulses of either polarity, zfCx 55.5 channels exhibited rapidly flickering activity without a pronounced or sustained substate conductance level. $E$, Gaussian best fits of the all-points histogram for the top recording shown in $D$ indicate a main state conductance of $57 \mathrm{pS}$ for zfCx55.5 channels.

opening. Plots of $G_{\mathrm{j}}$ versus $V_{\mathrm{j}}$ indicated that this behavior was asymmetrical, most notably in the conductance levels at the largest $V_{\mathrm{j}}\left(130\right.$ vs $162 \%$ of initial values for positive and negative $V_{\mathrm{j}}$, respectively). Thus, zfCx55.5 channels display a unique voltage dependence that sets them apart from all other connexins examined so far.

\section{Formation of heterotypic channels between retinal connexins}

Intercellular channels span two plasma membranes, each of which contributes a hemichannel or connexin. This situation implies that, depending on the connexin composition of the hemichannels, gap junctional channels may be homotypic when both cells express the same connexin, or heterotypic when each cell contributes a different connexin, and it has been shown that heterotypic compatibility among connexins is a selective process (Barrio et al., 1991; Bruzzone et al., 1993; Nicholson et al., 1993; Elfgang et al., 1995; White and Bruzzone, 1996). The ability of zebrafish connexins to form functional channels in heterotypic configurations was tested by pairing $\mathrm{zfCx} 27.5$ with $\mathrm{zfCx} 44.1$ and $\mathrm{zfCx} 55.5$, respectively, and zfCx44.1 with zfCx55.5. All combinations resulted in the development of junctional conductances that greatly exceeded background levels measured in antisense-treated control pairs (Fig. 7A). The general conclusion obtained from this series of experiments is that the three new fish connexins that are all expressed in the retina are compatible partners. The initial characterization of heterotypic channels revealed that, for each polarity, voltage dependence was qualitatively similar to that of the corresponding homotypic channels (Fig. 7B-D). Thus, zfCx27.5/zfCx44.1 channels showed an obvious asymmetry, with currents closing faster and with a lower threshold for relative positivity of the $\mathrm{zfCx} 44.1$ side, whereas the zfCx27.5-injected cell showed a higher voltage threshold and was much less sensitive to voltage gating (Fig. $7 B$ ). Some differences were also apparent. For example, in the case of $\mathrm{zfCx} 44.1$, voltage gating occurred with a much slower time course when paired to zfCx27.5, with respect to that observed in homotypic channels. In addition, zfCx27.5 displayed a reduced sensitivity to voltage and an increased residual conductance for polarizing steps of the same amplitude when paired heterotypically to either $\mathrm{zfCx} 44.1$ or zfCx55.5. In terms of their biophysical profiles, the $\mathrm{zfCx} 27.5 /$ zfCx55.5 and zfCx44.1/zfCx55.5 configurations are of considerable interest, because these heterotypic channels were extremely asymmetric. Thus, depolarization of the cell expressing either zfCx27.5 (Fig. 7C) or zfCx44.1 (Fig. 7D) showed a certain degree of voltagedependent closure, whereas increasing positivity of the cell expressing zfCx55.5 in both heterotypic configurations resulted in large increases in current amplitude (Fig. $7 C, D$ ). The functional consequence of this asymmetry is that heterotypic channels containing a homomeric zfCx55.5 connexin exhibit rectifying electrophysiological characteristics. 
Figure 9. In situ hybridization $(A-D)$ and in situ RT-PCR $(E, F)$ of carp and zebrafish connexins in the retina. $P E$, Pigment epithelium; $O N L$, outer nuclear layer; OPL: outer plexiform layer; $I N L$, inner nuclear layer; $I P L$, inner plexiform layer; $G C L$, ganglion cell layer. In the case of carpCx43 $(A)$, labeling is found mostly in the GCL and INL. $B$, High-resolution micrograph taken with differential interference contrast optics (DIC) of an area similar to the one depicted in $A$ by a box. The arrow points to a cell body that because of its localization is considered to represent an amacrine cell. $C, D$, Hybridization with a probe specific for zfCx $55.5 \mathrm{C}$ shows labeling in the GCL and INL. Note the labeled neurons at the border of the INL, which because of their localization and regular spacing could be horizontal cells (arrows). $D$, High-resolution micrograph with DIC optics of an area similar to that indicated by a box in $C$. The arrows point to a set of positive cells in the outer plexiform layer that exhibit axon terminal-like processes. $E$, $F$, In situ RT-PCR with primers specific for $\mathrm{zfCx} 27.5(E)$ and $\mathrm{zfCx} 44.1(F) . \mathrm{zfCx} 27.5$ shows discrete labeling of clusters of neurons in the inner nuclear layer (black arrows) and ganglion cell layer (white arrows), whereas $\mathrm{zfCx} 44.1$ is restricted to the ganglion cell layer (white arrows). Sections were counterstained with methyl-green to visualize the nuclear layers.

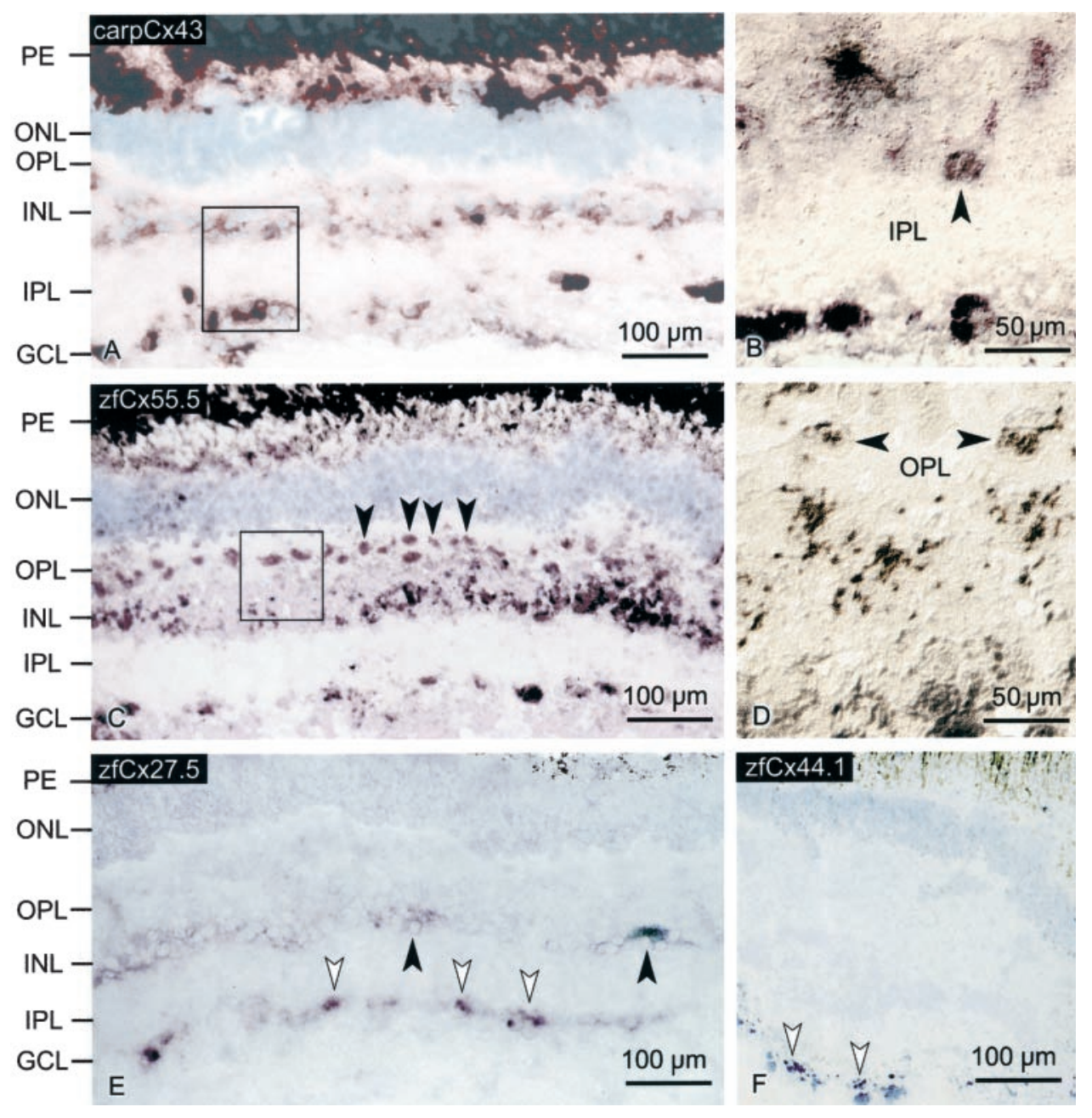

\section{Single-channel properties of homomeric zebrafish connexins}

Transient transfection of the three new zebrafish connexins into the communication-deficient N2A neuroblastoma cell line confirmed the general pattern of voltage sensitivity described above for junctional currents recorded in the paired oocyte expression assay. Moreover, these studies extended our data to the single-channel level. In the case of $\mathrm{zfCx} 27.5$, we recorded from 29 cell pairs in which total (macroscopic) junctional conductance $\left(g_{\mathrm{j}}\right)$ ranged from 0 (two cases) to $30 \mathrm{nS}$, and in five of these pairs, unitary currents were digitized at multiple voltages. From the slope of the $I-V$ relation, we measured a unitary conductance $\left(\gamma_{\mathrm{j}}\right)$ of $70-80 \mathrm{pS}$ for the fully open state and $15-20 \mathrm{pS}$ for the residual subconductance state at the highest voltages (Fig. $8 A$ ). For zfCx44.1, we recorded junctional currents from 24 cell pairs $\left(g_{\mathrm{j}}=0-30 \mathrm{nS}\right)$; five cell pairs exhibited one to three open channels, from which $\gamma_{\mathrm{j}}$ (main state) and $\gamma_{\mathrm{j}}$ (substate) were calculated as $270-280$ and $50-70 \mathrm{pS}$, respectively (Fig. $8 B, C)$. For zfCx55.5, 46 cell pairs $\left(g_{\mathrm{j}}=0-40 \mathrm{nS}\right)$ were recorded; in seven of these pairs, $\gamma_{\mathrm{j}}$ (main state) was calculated to be $\sim 50-60 \mathrm{pS}$, whereas substate conductance was poorly resolved in these pairs and was estimated to be $\leq 10 \mathrm{pS}$ (Fig. 8D,E).

\section{Retinal localization of the four cloned connexins}

The most interesting question arising from the cloning and functional expression work is whether retinal neurons show a cellspecific pattern of connexin expression. To obtain data on this issue, we performed in situ hybridization studies using the digoxigenin technique, which allows a resolution of positive signals for neuronal connexins at the single cell level (Simbürger et al., 1997). When cRNA probes specific for carpCx43 (see Materials and Methods) were used, prominent signals occurred in the ganglion cell layer and in the inner nuclear cell layer of the carp retina (Fig. $9 A$ ). The labeling pattern of carpCx43 in the inner nuclear layer revealed a restriction to single cells or cell groups, indicative of the presence of a subpopulation of carpCx43-expressing cells (Fig. 9B). In the ganglion cell layer, a definitive differentiation of glial cells from neurons was not possible, as indicated in Figure $9 A$. According to their size and position, however, a number of cells can be regarded as ganglion cells rather than astrocytes, which are the representative glial cell type in the ganglion cell layer.

zfCx55.5 revealed a labeling of cell bodies predominantly in the inner nuclear layer, with a staining of cells at the outer border, corresponding to the area where somata of horizontal cells are localized (Fig. 9C). A closer examination of these cells using differential interference contrast optics revealed features, i.e., prominent axon terminal and rounded cells bodies (Fig. 9D), that characterize them as horizontal cells. However, the spatial distribution with reactive-free areas between the cell bodies is suggestive for only a subtype of horizontal cells expressing zfCx55.5. A regular staining of cell bodies was also achieved in the ganglion cell layer.

Finally, we looked for the presence of zfCx27.5 and zfCx44.1 in fish retina. In situ hybridization failed to show any signals for either connexins (data not shown). This confirms the low level of expression of $\mathrm{zfCx} 27.5 \mathrm{RNA}$ and $\mathrm{zfCx} 44.1$ in adult fish retina, because Northern blots were also negative when hybridized with specific probes (see above). A discrete signal was obtained with in situ RT-PCR for both connexins. ZfCx27.5 showed a discrete labeling of subpopulations of neurons in the inner nuclear layer (Fig. 9E) and the ganglion cell layer, whereas zfCx44.1 exclusively labeled single cells in the ganglion cell layer (Fig. $9 F$ ). Apparently these connexins are expressed in a highly restricted pattern and are 
confined to subsets of cells in both neuronal layers. Further identification of the cell types associated with this labeling was not possible, however, and will require further experiments with immunocytochemistry, using specific antibodies directed to both connexins.

\section{DISCUSSION}

\section{Relationship of the new zebrafish connexins to the connexin gene family}

We have identified three zebrafish connexins, zfCx27.5, zfCx55.5, and $\mathrm{zfCx} 44.1$, which are expressed in fish retina. In addition, we have characterized the carpCx $43 \mathrm{cDNA}$ and used it as a probe for tissue localization.

The data presented in Figure $1 A-C$ provide evidence that the three zebrafish connexins represent novel genes, because multiple amino acid sequence alignments indicate significant differences in the cytoplasmic loop and C-terminal sequences between the three zebrafish connexins and rodent connexins that showed the highest homology scores.

Specifically, zfCx27.5 reveals an overall homology with rat $\mathrm{Cx} 26$ of $\sim 80 \%$. This homology is most evident in the transmembrane domains (M1-M4); substantial differences occur in the cytoplasmic loop sequence and the $\mathrm{C}$ terminus. The latter is characterized by a stretch of 22 amino acids at the very end of $\mathrm{zfCx} 27.5$, interrupted by seven amino acids with low homology (aa 221-228), which extends this connexin by $\sim 1.5 \mathrm{kDa}$. In addition, zfCx 27.5 exhibits a consensus sequence for casein kinase II phosphorylation (aa SPKD, position 53-66 of the putative cytoplasmic loop), which is consistently found in all connexins except mammalian Cx26. The phylogenetic dendrogram places zf 27.5 into the $\beta$-group of connexins not distant from rat Cx32 (Fig. 10). Support for the notion that mammalian $\mathrm{Cx} 26$ and zfCx27.5 are different genes is further provided by the functional expression data. In oocyte and transfected mammalian cell lines, $\mathrm{Cx} 26$ displays weak voltage sensitivity with a $V_{0}$ of approximately $\pm 100 \mathrm{mV}$ (Barrio et al., 1991) and large conductance $(\sim 120-140 \mathrm{pS})$ channels (Bukauskas et al., 1995). By contrast, zfCx27.5 exhibited moderate voltage-dependent channels. Thus, the calculated half-maximal decrease of steady-state junc-

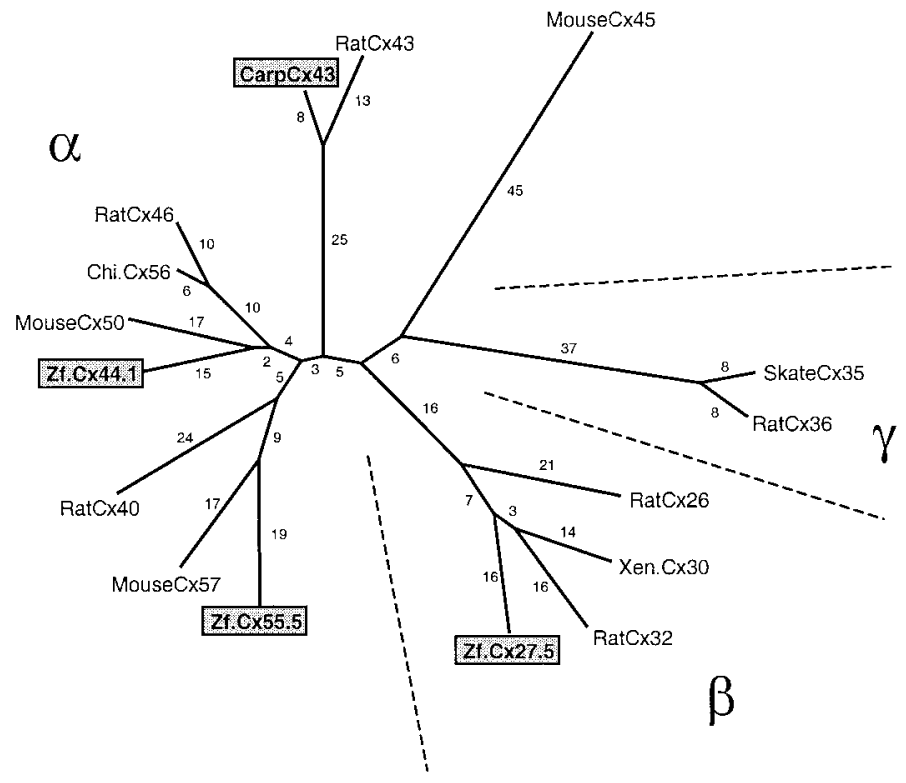

Figure 10. Unrooted phylogenetic tree of a multiple peptide sequence alignment of the novel carp and zebrafish connexins and known connexin types. The dendrogramm was created with the AllAll software from the website of the Computional Biochemistry Research Group (http://cbrg. inf.ethz.ch). The similarity scores and pairwise matches of all specified sequences were obtained by running a complete dynamic programming algorithm equivalent to Smith-Waterman. The complete amino acid sequences were included in the alignment. $\mathrm{zfCx} 27.5$ is placed within the $\beta$-subgroup, whereas the others (carpCx43, zfCx44.1, and $\mathrm{zfCx} 55.5)$ match with the $\alpha$-subgroup of the connexin gene family. tional conductance occurred at transjunctional voltages smaller than $\pm 40 \mathrm{mV}$, and unitary conductance of single channels was in the range of $60 \mathrm{pS}$. Although few of the $\beta$-group of connexins have been analyzed to date, these properties are more similar to those of Cx32 than Cx26.

zfCx55.5 is a more distant relative among the new zebrafish connexins. It exhibits the highest homology score with mouse Cx57 $(55.2 \%)$. The dendrogram (Fig. 10) shows that zfCx55.5 is a member of the $\alpha$-group placed between rodent Cx57 and Cx46. Singlechannel studies revealed that unitary conductances for zfCx55.5 channels are closer to those recently described for $\mathrm{Cx} 57$ than to Cx46 (Manthey et al., 1999).

zfCx44.1 offers some particular features. It reveals the closest homology with mouse and human Cx50 (71 and 69\%, respectively). Significant differences between the lens fiber proteins and $\mathrm{zfCx} 44.1$ occur in the putative cytoplasmic loop region and at the $\mathrm{C}$ terminus. Because mRNA of $\mathrm{zfCx} 44.1$ was not detectable on Northern blots including lens but amplified in RT-PCR, zfCx44.1 seems less likely to represent a dominant connexin in fish lens fibers as is the case for Cx50 in mammals. However, an orthology of both genes cannot be excluded.

According to our genomic cloning, the gene structure of all three new zebrafish connexins is of the conventional type. None of them showed an interruption of the coding region of the exon as is the case for the $\gamma$-group, which includes the retinal skate $\mathrm{Cx} 35$, perch Cx34.7 (O'Brien et al., 1996, 1998), and mouse Cx36 (Condorelli et al., 1998; Söhl et al., 1998). A reasonable explanation for the lack of any member of the $\gamma$-group in our cloning approach is the fact that we used the band of our RT-PCR amplification products that corresponds to amplified sequences between 350 and $480 \mathrm{bp}$. One of the essential differences between the primary sequence of the $\gamma$-group and the conventional connexins ( $\alpha$ - and $\beta$-group, excluding Cx45) is the length of the cytoplasmic loop. RT-PCR fragments of the $\gamma$-group seem to migrate at a higher molecular base position (Condorelli et al., 1998). Thus amplification of this region results in a segregation of connexins into $\alpha / \beta$-group and $\gamma$-group connexins.

\section{Localization and functional expression}

Initial answers to the question of functional diversity of retinal gap junctions based on our molecular approach can be obtained by considering the expression sites and the electrophysiological data derived from the paired Xenopus oocyte expression system and transient transfections of N2A cells.

zfCx44.1 and zfCx27.5 showed the lowest levels of expression. A definitive attribution of these connexins to neural cell types could not be obtained from their in situ localization because of their very restricted expression in the inner nuclear layer and ganglion cell layer. Some aspects of $\mathrm{zfCx} 44.1$, however, are of interest with respect to its functional properties. The expression data indicate that $\mathrm{zfCx} 44.1$ has a steep voltage dependence that was prevalent in Xenopus oocytes and in transiently transfected N2A neuroblastoma cells. Unitary conductance is $\sim 280 \mathrm{pS}$, with substates of $50-70 \mathrm{pS}$. The electrophysiology of this channel resembles the electrophysiological properties of murine $\mathrm{Cx} 50$, which has macroscopic and unitary currents profiles similar to those of zfCx44.1 (Srinivas et al., 1999a).

carpCx43 cRNA showed expression at various sites in fish retina. Our in situ hybridization data confirmed results reported by immunocytochemical staining of carp retina (Janssen-Bienhold et al., 1998). Some discrepancies in the staining pattern between the original immunofluorescence work (Janssen-Bienhold et al., 1998) and the in situ hybridization data may result from differences in the localization of the reaction products because the cRNA is localized preferentially in the cell bodies, whereas the immunolabeling is expected to stain the gap junction protein in both the somata and their peripheral processes. Remarkably, Cx43 cRNA expression was prevalent in subsets of cells in the ganglion cell layer as well as in the inner plexiform layer at sites of amacrine cell localization (Fig. 9B). Although a definite differentiation of the subtypes of retinal neurons expressing carpCx43 requires double labeling with 
cell-specific markers, it is obvious that this connexin is expressed in a cell-restricted pattern indicative for the existence of networks of functionally distinct electrically coupled neurons. This becomes even more apparent when the expression of $\mathrm{zfCx} 55.5$ is taken into account. In contrast to carpCx43, zfCx55.5 cRNA, in addition to its expression in the ganglion cell layer and inner nuclear layer, was prevalent in a band of regularly spaced cells that according to their localization and spatial distribution could represent horizontal cells. Because enriched mRNA from horizontal cells was used as a source for PCR amplification, labeling of this functionally coupled cell population was not entirely unexpected. Moreover, the unitary conductance of $\mathrm{zfCx} 55.5$ is in agreement with the electrophysiological data reported for gap junction channels in horizontal cells (DeVries and Schwartz, 1989; Lu et al., 1999). Furthermore, zfCx55.5 exhibits a unique feature that has not been reported for any other gap junction channel thus far. Instead of closing in response to transjunctional voltage, $\mathrm{zfCx} 55.5$ is characterized by a voltage-induced opening in homotypic configuration, making this connexin a likely candidate to participate in the formation of rectifying junctions in heterotypic settings. In fact, when $\mathrm{zfCx} 55.5$ was paired with two other connexins that both show voltagedependent decay of junctional current (zfCx27.5 and $\mathrm{zfCx} 44.1)$, a remarkable polarization of channel conductance occurred. This is reminiscent of the rectification as described in the original contributions of Furshpan and Potter (1959) and Auerbach and Bennett (1969). Because zfCx55.5 revealed high levels of expression in different layers of the retina where it can interact with other connexins in heterotypic configurations, such rectifying synapses may well exist in in vivo situations. The stratified structure of the retina and the experimental accessibility of the ganglion cell layer should allow proof of its existence in in vivo preparations.

With respect to tissue-specific expression, it is of interest that retinal neurons apparently express connexins of the conventional as well as the $\gamma$-group type. Two distinct features of the neuronal connexins belonging to the $\gamma$-branch are their weak voltage sensitivity together with the inability to functionally interact with connexins of the $\alpha$ - or $\beta$-subgroups (O'Brien et al., 1998; Srinivas et al., 1999b; Al-Ubaidi et al., 2000). The high threshold of voltage inactivation (e.g., $\sim 70 \mathrm{mV}$ for perch Cx35 and $\sim 100 \mathrm{mV}$ for mouse $\mathrm{Cx} 36)$, together with the large residual conductances measured at the largest transjunctional voltages, had suggested that electrical coupling between retinal neurons may not be easily disrupted by shifts in membrane potential that occur during periods of visual activity. The general electrophysiological properties of the new connexins described here, however, clearly indicate that neurons are also endowed with voltage-sensitive electrical synapses and that multiple connexins with the potential for compatible heterotypic channel formation are likely to shape the functional connectivity of retinal circuits.

\section{REFERENCES}

Al-Ubaidi MR, White TW, Ripps H, Poras I, Avner P, Gomès D, Bruzzone R (2000) Functional properties, developmental regulation and chromosomal localization of murine connexin36, a gap-junctional protein expressed preferentially in retina and brain. J Neurosci Res 59:813-826.

Auerbach AA, Bennett MVL (1969) A rectifying electrotonic synapse in the central nervous system of a vertebrate. J Gen Physiol 53:211-237.

Baldrige WH, Vaney DI, Weiler R (1998) The modulation of intercellular coupling in the retina. Semin Cell Dev Biol 9:311-318.

Banach K, Weingart R (1996) Connexin43 gap junctions exhibit asymmetrical gating properties. Pflügers Arch 431:775-785.

Barrio LC, Suchyna T, Bargiello T, Xu LX, Roginski RS, Bennett MVL (1991) Gap junction formed by connexin 26 and 32 alone and in combination are differently affected by applied voltage. Proc Natl Acad Sci USA 88:8410-8414.

Becker D, Bonness V, Mobbs P (1998) Cell coupling in the retina: pattern and purpose. Cell Biol Int 22:781-792.

Bennett MVL, Barrio TA, Bargiello TA, Spray DC, Hertzberg E, Sáez JC (1991) Gap junctions: new tools, new answers, new questions. Neuron 6:305-320.

Bruzzone R, Haefliger JA, Gimlich RL, Paul DL (1993) Connexin40, a component of gap junctions in vascular endothelium, is restricted in its ability to interact with other connexins. Mol Biol Cell 4:7-20.

Bruzzone R, White TW, Paul DL (1996) Connections with connexins: the molecular basis of direct intercellular signaling. Eur J Biochem 238:1-27.
Bukauskas F, Elfgang C, Willecke K, Weingart R (1995) Heterotypic gap junction channels (connexin26-connexin32) violate the paradigm of unitary conductance. Pflügers Arch 429:870-872.

Chomczynsky P, Sacchi N (1987) Single step method of RNA isolation by guanidinium thiocyanytephenolchloroform extraction. Anal Biochem 162:156-159.

Condorelli DF, Parenti R, Spinella F, Salinaro AT, Belluardo N, Cardile V, Cicirata F (1998) Cloning of a new gap junction gene (Cx36) highly expressed in mammalian brain neurons. Eur J Neurosci 10:1202-1208.

Dahl G, Miller T, Paul DL, Voellmy R, Werner R (1987) Expression of functional cell-cell channels from cloned rat liver gap junction complementary DNA. Science 236:1290-1293.

Dermietzel R, Spray DC (1993) Gap junctions in the brain: where, what type, how many and why? Trend Neurosci 16:186-192.

DeVries SH, Schwartz EA (1989) Modulation of electrical synapse between solitary pairs of catfish horizontal cells by dopamine and second messengers. J Physiol (Lond) 414:351-375.

Dowling JE, Brown JE, Major D (1966) Synapses of horizontal cells in rabbit and cat retinas. Science 153:1639-1641.

Elfgang C, Ekkert R, Lichtenberg-Frate H, Butterweck A, Traub O, Klein RA, Huelser DF, Willecke K (1995) Specific permeability and selective formation of gap junction channels in connexin-transfected HeLa cells. J Cell Biol 129:805-817.

Furshpan EJ, Potter DD (1959) Transmission at the giant motor synapse of the crayfish. J Physiol (Lond) 145:289-325.

Galarreta W, Hestrin S (1999) A network of fast-spiking cells in the neocortex connected by electrical synapses. Nature 402:72-75.

Gibson JR, Beierlein M, Connors BW (1999) Two networks of electrically coupled inhibitory neurons in neocortex. Nature 402:75-79.

Haefliger J-A, Bruzzone R, Jenkins NA, Gilbert DJ, Copeland NG, Paul DL (1992) Four novel members of the connexin family of gap junction proteins. Molecular cloning, expression and chromosome mapping. J Biol Chem 267:2057-2064.

Hampson EC, Weiler R, Vaney DI (1994) pH-gated dopaminergic modulation of horizontal cell gap junctions in mammalian retina. Proc R Soc Lond B Biol Sci 255:67-72.

Janssen-Bienhold U, Nagel H, Weiler R (1993) In vitro phosphorylation in isolated horizontal cells of the fish retina: effects of the state of light adaptation. Eur J Neurosci 5:584-593.

Janssen-Bienhold U, Dermietzel R, Weiler R (1998) Distribution of connexin43 immunoreactivity in the retinas of different vertebrates. J Comp Neurol 396:310-321.

Krieg PA, Melton PA (1984) Functional messenger RNAs are produced by SP6 in vitro transcription of cloned cDNAs. Nucleic Acids Res 12:7057-7070.

Kumar NM, Gilula NB (1996) The gap junction channel. Cell 84:381-388. Lasater EM (1987) Retinal horizontal cell gap junctional conductance is modulated by dopmaine through a cyclic AMP-dependent protein kinase. Proc Natl Acad Sci USA 84:7319-7323.

Lu C, Zhang D-Q, McMahon DG (1999) Electrical coupling of retinal horizontal cells mediated by distinct voltage-independent junctions. Vis Neurosci 16:811-818.

Manthey D, Bukauskas F, Lee CG, Kozak CA, Willecke K (1999) Molecular cloning and functional expression of the mouse gap junction gene connexin-57 in human HeLa cells. J Biol Chem 274:14716-14723.

Methfessel C, Witzemann V, Takahashi T, Mishina M, Numa S, Sakmann B (1986) Patch clamp measurements on Xenopus laevis oocytes: currents through endogenous channels and implanted acetylcholine receptor and sodium channels. Pflügers Arch 407:577-588.

Milks LC, Kumar NM, Houghton R, Unwin N, Gilula NB (1988) Topology of the 32-kd liver gap junction protein determined by site-directed antibody localizations. EMBO J 7:2967-2975.

Mills SL, Massey SC (1995) Differential properties of two gap junctional pathways made by AII amacrine cells. Nature 377:734-738.

Nicholson BR, Dermietzel R, Teplow D, Traub O, Willecke K, Revel J-P (1987) Two homologous protein components of hepatic gap junctions. Nature 329:732-734.

Nicholson BR, Suchyna T, Xu LX, Hammernick P, Cao FL, Fourtner C, Barrio L, Bennett MVL (1993) Divergent properties of different connexins expressed in Xenopus oocyte. Prog Cell Res 3:3-13.

O'Brien J, Al-Ubaidi MR, Ripps H (1996) Connexin35: a gap junctional protein expressed preferentially in the skate retina. Mol Biol Cell 7:233-243.

O‘Brien J, Bruzzone R, White TW, Al-Ubaidi MR, Ripps H (1998) Cloning and expression of two related connexins from the perch retina define a distinct subgroup of the connexin family. J Neurosci 18:7625-7637.

Piccolino M, Neyton J, Witkovsky P (1982) $\gamma$-aminobutyric acid antagonists decrease junctional communication between L-horizontal cells of the retina. Proc Natl Acad Sci USA 79:3671-3675.

Ressot C, Gomes D, Dautigy A, Pham-Dinh D, Bruzzone R (1998) Connexin32 mutations associated with X-linked Charcot-Marie-Tooth disease show two distinct behaviors: loss of function and altered gating properties. J Neurosci 18:4063-4075.

Sambrook J, Fritsch EF, Maniatis T (1989) Molecular cloning: a laboratory manual. Cold Spring Harbor, NY: Cold Spring Harbor Laboratory. Simbürger E, Stang A, Kremer M, Dermietzel R (1997) Expression of 
connexin43 mRNA in adult rodent brain. Histochem Cell Biol 107:127-137.

Söhl G, Degen J, Teubner B, Willecke K (1998) The murine gap junction gene connexin 36 is highly expressed in mouse retina and regulated during brain development. FEBS Lett 428:27-31.

Spray DC (1996) Physiological properties of gap junction channels in the nervous system. In: Gap junctions in the nervous system (Spray DC, Dermietzel R, eds), pp 39-59. Austin, TX: R. G. Landes.

Spray DC, Harris AL, Bennett MVL (1981) Equilibrium properties of a voltage-dependent junctional conductance. J Gen Physiol 77:77-93.

Srinivas M, Costa M, Gao Y, Fort A, Fishman GI, Spray DC (1999a) Voltage dependence of macroscopic and unitary currents of gap junction channels formed by mouse connexin50 expressed in rat neuroblastoma cells. J Physiol (Lond) 517:673-689.

Srinivas M, Rozental R, Kojima T, Dermietzel R, Mehler M, Condorelli DF, Kessler JA, Spray DC (1999b) Functional properties of channels formed by the neuronal gap junction protein connexin36. J Neurosci 19:9848-9855.

Swenson KI, Jordan JR, Beyer EC, Paul DL (1989) Formation of gap junctions by expression of connexins in Xenopus oocyte pairs. Cell $57: 145-155$.

Vaney DI (1991) Many diverse types of retinal neurons show tracer coupling when injected with biocytin or Neurobiotin. Neurosci Lett 125:187-190.

Vaney DI (1993) The coupling pattern of axon-bearing horizontal cells in the mammalian retina. Proc R Soc Lond B Biol Sci 252:93-101.

Vaney DI (1994) Patterns of neuronal coupling in the retina. Prog Ret Eye Res 13:301-353.
Vaney DI (1996) Cell coupling in the retina. In: Gap junctions in the nervous system (Spray DC, Dermietzel R, eds), pp 79-102. Austin, TX: R. G. Landes.

Veenstra RD (1996) Size and selectivity of gap junction channels formed from different connexins. J Bioenerg Biomembr 28:327-337.

Wagner TL, Beyer EC, McMahon DG (1998) Cloning and functional expression of a novel gap junction channel from the retina of Danio aquipinnatus. Vis Neurosci 15:1173.

Weiler R (1996) The modulation of gap junction permeability in the retina. In: Gap junctions in the nervous system (Spray DC, Dermietzel R, eds), pp 103-121. Austin, TX: R. G. Landes.

Weiler R, He SG, Vaney DI (1999) Retinoic acid modulates gap junctional permeability between horizontal cells of the mammalian retina. Eur J Neurosci 11:3346-3350.

White TW, Bruzzone R (1996) Multiple connexin proteins in single intercellular channels: connexin compatibility and functional consequences. J Bioenerg Biomembr 28:339-350.

White TW, Bruzzone R, Wolfram S, Paul DL, Goodenough DA (1994) Selective interaction among the multiple connexin proteins expressed in the vertebrate lens: the second extracellular domain is a determinant of compatibility between connexins. J Cell Biol 125:879-892.

Wilders R, Jongsma HJ (1992) Limitations of the dual voltage clamp method in assaying conductance and kinetics of gap junction channels. Biophys J 63:942-953.

Wolburg H, Kurz-Isler G (1996) Modulation of connexin density in gap junctions of fish horizontal cells. In: Gap junctions in the nervous system (Spray DC, Dermietzel R, eds), pp 123-133. Austin, TX: R. G. Landes. 